\title{
Springer
}

\section{TRPC3/6/7 Knockdown Protects the Brain from Cerebral Ischemia Injury via Astrocyte Apoptosis Inhibition and Effects on $\mathrm{NF}-\mathrm{\kappa B}$ Translocation}

\author{
Molecular Neurobiology \\ December 2017, Volume 54, Issue 10, pp 7555
}

-7566 | Cite as

\section{Article}

\section{First Online: 08 November 2016}

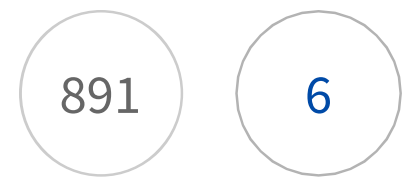

\section{Abstract}

Ischemia contributes significantly to morbidity and mortality associated with many common neurological diseases. Calcium overload is an important mechanism of cerebral ischemia and reperfusion (I/R) injury. Despite decades of intense research, an effective beneficial treatment of stroke remains limited; few therapeutic strategies exist to combat the consequences of cerebral ischemia. Traditionally, a "neurocentric" view has dominated research in this field. Evidence is now accumulating that glial cells, especially astrocytes, play an important role in the pathophysiology of cerebral ischemia. Here, we show that transient receptor potential (TRP) $\mathrm{C}_{3} / 6 / 7$ knockout (KO) mice subjected to an I/R procedure demonstrate ameliorated brain injury (infract size), compared to wild-type (WT) control animals. This is accompanied by reduction of NF- $\mathrm{KB}$ phosphorylation and an increase in protein kinase $\mathrm{B}$ (AKT) phosphorylation in I/R-injured brain tissues in TRPC $3 / 6 / 7$ KO mice. Also, the expression of pro-apoptotic protein Bcl-2 associated X (Bax) is down-regulated and that of anti-apoptotic protein Bcl-2 is upregulated in $\mathrm{TRPC}_{3} / 6 / 7^{-/-}$mice. Astrocytes isolated from TRPC $3 / 6 / 7 \mathrm{KO}$ mice and subjected to oxygen/glucose deprivation and subsequent reoxygenation (OGD-R, mimicking in vivo I/R injury) also exhibit enhanced Bcl-2 expression, reduced Bax expression, 
enhanced AKT phosphorylation, and reduced NF-кB phosphorylation. Furthermore, apoptotic rates of $\mathrm{TRPC}_{3} / 6 / 7 \mathrm{KO}$ astrocytes cultured in OGD-R conditions were reduced significantly compared to WT control. These findings suggest TRPC3/6/7 channels play a detrimental role in brain I/R injury. Deletion of these channels can interfere with the activation of NF-кB (pro-apoptotic), promote activation of AKT (anti-apoptotic), and ultimately, ameliorate brain damage via inhibition of astrocyte apoptosis after cerebral ischemia/reperfusion injury.

\section{Keywords}

Astrocyte Cerebral ischemia TRPC3/6/7 NF-кB

Xiaoyun Chen and Min Lu contributed equally to this work

\section{Access to this content is enabled by National Institutes of Health Library}

\section{Introduction}

Stroke is a central nervous system disease with the highest mortality and disability rates, which cause serious damage to human health. Stroke is mainly classified into hemorrhagic stroke and ischemic stroke. Over the past years, much effort has gone into prevention and treatment of stroke, such as thrombolysis, anti-coagulation, emergency intervention, and minimally invasive surgery, and greatly improved the prognosis of patients with stroke. But $75 \%$ of the patients still suffer from varying degrees of sequelae. Recanalization that is promoted happens in about $30 \%$ of ischemic stroke patients upon thrombolysis therapy. The progressive injury following stroke originates from complex pathologic mechanisms, including calcium overload, energy exhaustion, excitotoxicity, oxidative stress, inflammation, and apoptosis $[\underline{1}, \underline{2}$ $, \underline{3}, \underline{4}, \underline{5}]$. With respect to cell death, toxic intracellular accumulation of calcium plays an important role in the phenomenon of cerebral ischemia and reperfusion injury [ $\underline{6}$, 7, $\underline{8}]$.

Astrocytes are the most abundant non-neuronal cell type in the central nervous system and constitute up to $50 \%$ of total human brain cells. Neurons cannot survive in the brain without close interaction with astrocytes. Accordingly, astrocyte function can critically influence neuronal survival during ischemia and other brain insults [ $\underline{9}$, $\underline{10}, \underline{11}, \underline{12}]$. Several molecular pathways are involved in astrocyte apoptosis, such as $\mathrm{Ca}^{2+}$ overload, mitochondrial dysfunction, and oxidative stress. Thus, it is a very effective approach to protect the central nervous system in ischemia and reperfusion (I/R) injury by preventing astrocytes from cell apoptosis [ $\underline{13}]$. 
C-type of transient receptor potential (TRPC) channels belong to the TRP superfamily. The TRPC subfamily has seven members in mammals (TRPC1-7) which participate in store-operated calcium entry (SOCE) and/or receptor-operated calcium entry (ROCE) in various cell types, including astrocytes, and play a critical role in many cellular processes [14]. TRPC1-TRPC6 are expressed in cultured embryonic astrocytes $[\underline{15}, \underline{16}]$. TRPC1 and TRPC 3 likely contribute to SOCE in astrocytes, induced by endoplasmic reticulum depletion or metabotropic stimulation $[\underline{17}, \underline{18}]$. TRPC6 is involved in ROCE in cultured embryonic cortical astrocytes [19]. The aim of this work was to explore the roles of TRPC $3 / 6 / 7$ subgroup in brain ischemic injury, specifically to examine the impact of the combined TRPC $3 / 6 / 7$ deletion on astrocyte survival in cerebral ischemia reperfusion injury.

\section{Materials and Methods}

\section{Materials and Animals}

Sources of reagents and antibodies included the following: Fura2-AM (Invitrogen), FBS (GIBCO), protease inhibitor cocktail (Roche), anti-p-NF-кB (Ser-529) (Santa Cruz), anti-NF-кB (Santa Cruz), anti-Bcl-2-associated X (Bax) (Cell Signaling), antiBcl2 (Cell Signaling), anti-cleaved caspase 3 (abcam), anti-phosphorylated protein kinase B (p-AKT) (Ser-473) (Cell Signaling), and anti-AKT (Cell Signaling), anti- $\beta$ actin (abcam).

TRPC3/6/7-deficient mice on a mixed $\mathrm{C}_{57} \mathrm{BL} / 6 \mathrm{~J}-129 \mathrm{SvEv}$ background were reconstituted from cryopreserved embryos. TRPC3/6/7 triple knockout (KO) parents

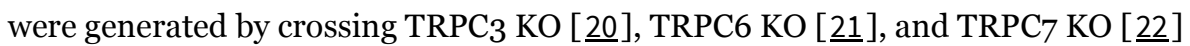
mice to the desired homozygosity at the Comparative Medicine Branch (CMB) of the National Institute of Environmental Health Sciences, North Carolina [므, 21]. Wildtype (WT) $\mathrm{C} 57 \mathrm{BL} / 6 \mathrm{~J} / 129 \mathrm{SvEv}$ mice also reconstituted from frozen embryos served as controls for the KO mice. Age-matched KO and WT controls were used for all studies. Animals were treated in compliance with the Guide for the Care and Use of Laboratory Animals (National Academy of Science). Animals were kept on a 12-h light-dark cycle in a temperature-controlled room with ad libitum access to food and water. All animal studies were approved by the Animal Care and Utilization Committee of Huazhong University of Science and Technology. Anesthetic procedures were used in full to ensure that animals do not suffer unduly during and after the experimental procedure. The genotype of TRPC $3 / 6 / 7$ triple KO was confirmed by PCR and RT-PCR as shown in Fig. 1a, b.
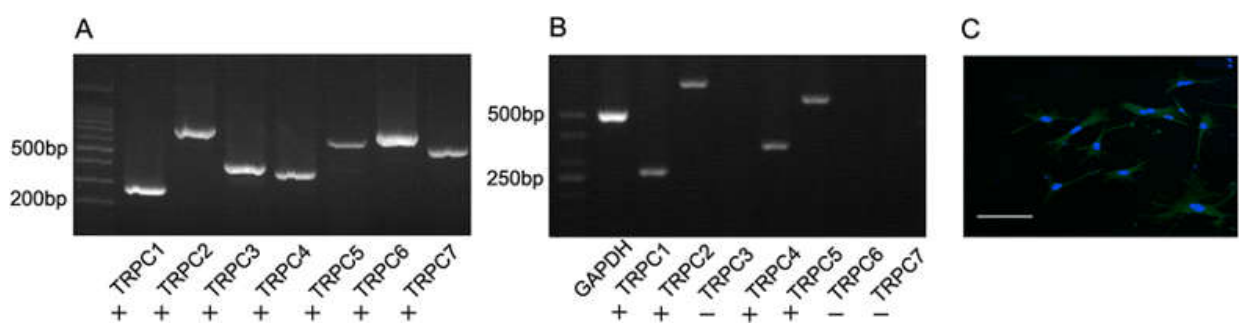


\title{
Fig. 1
}

TRPC3/6/7 gene knockout and positive control were confirmed by RT-PCR analysis of mRNA isolated from the mouse brain. a RT-PCR analysis for TRPC1-TRPC7 mRNA in WT mouse brain was used as a positive control. $\mathbf{b}$ RT-PCR analysis for TRPC1-TRPC7 mRNA in TRPC3/6/7 knockout mouse brain. c GFAP positive cells in primary cortical culture astrocytes. Astrocyte marker GFAP (green), DAPI (blue). Scale bar c: $50 \mu \mathrm{m}$

\author{
Surgical Procedures for Middle Cerebral Artery Occlusion
}

Focal cerebral ischemia was induced by occluding the middle cerebral artery (MCAO), as reported previously [23] . After animals were anesthetized with chloral hydrate, a nylon filament (10 $\mathrm{mm}$ total length and $0.22 \pm 0.11 \mathrm{~mm}$ diameter) was inserted in the internal carotid artery. One hour later, the filament was removed to commence reperfusion for $24 \mathrm{~h}$. Animals were distributed into groups as follows: WT sham group (control), WT model group, TRPC $3 / 6 / 7^{-/-}$sham group (control), and $\mathrm{TRPC}_{3} / 6 / 7^{---}$model group. In the sham group, the external carotid artery was dissected, but the filament was not inserted.

\section{Primary Astrocyte Culture}

Primary astrocytes were isolated from the cerebral cortices of 3-day-old mice, as described previously [24]. Briefly, the dissociated cortical cells were suspended in DMEM-F12, containing 100 units/mL penicillin, $100 \mu \mathrm{g} / \mathrm{mL}$ streptomycin, and $15 \%$ fetal bovine serum. Cells were then placed into poly- $L$-lysine-coated culture flasks at a density $6 \times 10^{6}$ cells $/ \mathrm{cm}^{2}$. Astrocytes were obtained by the shaking method after 12 -14 days of culture. Non-astrocytes, such as microglia and oligodendrocytes, were removed from the flasks. In these cultures, more than $98 \%$ of the cells are positive for glial fibrillary acidic protein (GFAP), an astrocyte marker (Fig. 11). Astrocytes in the flasks were dislodged with $0.25 \%$ trypsin and plated in different culture dishes for further experiments.

The Oxygen and Glucose Deprivation Model 
Astrocyte cultures were subjected to oxygen and glucose deprivation (OGD) followed by reoxygenation, to mimic the in vitro ischemic-like condition. For the OGD condition, the culture medium was replaced with glucose-free DMEM pretreated with $95 \% \mathrm{~N}_{2} / 5 \% \mathrm{CO}_{2}$ atmosphere and cells were maintained in an hypoxic chamber $\left(95 \% \mathrm{~N}_{2} / 5 \% \mathrm{CO}_{2}, 37^{\circ} \mathrm{C}\right.$ ) for $12 \mathrm{~h}$. Reoxygenation was achieved by placing OGDtreated cells in glucose-containing DMEM/F12 under normoxic condition for $4 \mathrm{~h}$ (OGD-reoxygenation (R)). Further in vitro analysis was performed with OGD-Rtreated cell samples. Control astrocytes were maintained in a complete DMEM medium and incubated in a normoxic conditions throughout experiments (blank control). Astrocytes were assigned to four groups: WT control, WT OGD-R, $\mathrm{TRPC}_{3} / 6 / 7^{-/-}$control, and TRPC $3 / 6 / 7^{-/-}$OGD-R.

\section{Flow Cytometric Apoptosis Assay}

Apoptosis rates were measured by flow cytometry using the AnnexinV-fluorescein isothiocyanate (FITC)/PI apoptosis detection kit (BioVision, USA), as described [25] . After treatment with or without OGD-R, cells were collected at a concentration of $1 \times 10^{5}$ cells $/ \mathrm{mL}$ (total $8 \mathrm{~mL}$ for each), mixed with Annexin V-FITC and propidium iodide according to manufacturer's recommendation, and analyzed using a flow cytometer. Data were analyzed using the Cell Quest software (BD Biosciences, USA).

\section{Modified Neurological Severity Score Tests}

After 1 hour ischemic insult and $24 \mathrm{~h}$ reoxygenation, the neurological deficit scores of model animals were determined in a blinded manner according to the following graded scoring system: 0 , no neurological deficit; 1 , failure to extend left; 2 , circling to the left side; 3 , falling to the left side; and 4, did not walk independently and loss of consciousness [르].

\section{2,3,5-Triphenyltetrazolium Chloride Staining}

Mice were anesthetized with chloral hydrate and decapitated after $24 \mathrm{~h}$ of reperfusion. The brains were quickly removed and chilled at $-20{ }^{\circ} \mathrm{C}$ for $10 \mathrm{~min}$ and then, five consecutive $1 \mathrm{~mm}$-thick slices were cut with a metallic brain matrix. The brain slices were stained with $1 \%$ 2,3,5-triphenyltetrazolium chloride (TTC) at $37^{\circ} \mathrm{C}$ for $15 \mathrm{~min}$ in dark and then fixed in $4 \%$ paraformaldehyde for $1 \mathrm{~h}$. The unstained area of the brain slice was defined as infarction, whereas normal tissue was stained as red; infarct volume ratio was measured and calculated as described [27] .

\section{Quantitative PCR}

After reverse transcription of total RNA to cDNA using PrimeScript RT Reagent Kit (TaKaRa), real-time quantitative PCR was performed using the StepOne Real-Time PCR system (Applied Biosystems) in a final volume of $20 \mu \mathrm{L}$ containing $0.5 \mu \mathrm{g}$ of total RNA with Power SYBR Green PCR Master Mix (Applied Biosystem). Primer 
pairs used for each gene are as follows: $\beta$-actin, 5 -CTGAGAGGGAAATCGTGCGT-3 and 5 -CCACAGGATTCCATACCCAAGA- 3 ; Bax, 5

-AGACAGGGGCCTTTTTGCTAC-3 and 5 -AATTCGCCGGAGACACTCG; and Bcl-2, 5 -CCGGGAGAACAGGgTATGATAA-3 and 5 -CCCACTCGTAGCCCCTCTG-3 . The temperature cycles were $95{ }^{\circ} \mathrm{C}$ for $10 \mathrm{~min}$, followed by 40 cycles of $95{ }^{\circ} \mathrm{C}$ for $15 \mathrm{~s}$ and $60^{\circ} \mathrm{C}$ for 60 . The results were analyzed with Primer Express software (Applied Biosystem). The identity of the PCR product was confirmed by automated determination of the melting temperature of the PCR products. The results for each gene were normalized relative to $\beta$-actin messenger RNA (mRNA) levels measured in parallel in each sample.

\section{Immunofluorescence}

After fixation with $4 \%$ paraformaldehyde, astrocytes cells were permeabilized with $0.1 \%$ Triton-X and blocked with $3 \%$ BSA in PBS for 30 min; then cells were incubated with anti-p65 and GFAP monoclonal antibodies overnight at $4{ }^{\circ} \mathrm{C}$, washed in PBS for three times (10 min each time), and followed by incubation with goat antirabbit FITC. Nuclei were stained with 4 ,6-diamidino-2-phenylindole (DAPI) in PBS for $5 \mathrm{~min}$. All slides were examined with an epifluorescence microscope (Olympus FV500).

\section{Western Blot Analysis}

Lysates from cultured astrocytes cells and brain tissues were prepared at $4{ }^{\circ} \mathrm{C}$. Fifty micrograms of total proteins were resolved in SDS-PAGE and then transferred to a nitrocellulose membrane. Membranes were blocked with $5 \%$ skim milk in TBS-T and incubated with the respective primary antibody (AKT, p-AKT, NF-KB, p-NF-кB, Bcl-2, Bax, $\beta$-actin) for $24 \mathrm{~h}$ at $4{ }^{\circ} \mathrm{C}$. Then, membranes were detected with conjugated goat secondary antibody and signals were detected with an ECL kit.

\section{$\mathrm{Ca}^{2+}$ Imaging}

For measurement of $\left[\mathrm{Ca}^{2+}\right]$, astrocytes were cultured on polylysine-coated coverslips for $24 \mathrm{~h}$ and loaded with $2 \mu \mathrm{M}$ Fura2-AM by incubation for $35 \mathrm{~min}$ in a complete culture medium at $37^{\circ} \mathrm{C}$, then washed with Hepes buffered saline solution (HBSS) twice at room temperature. The HBSS contained (in $\mathrm{mM}$ ) $140 \mathrm{NaCl}, 5 \mathrm{KCl}, 1 \mathrm{MgCl}_{2}, 2$ $\mathrm{CaCl}_{2}, 10$ glucose, and 10 HEPES (pH 7.4). $\left[\mathrm{Ca}^{2+}\right]_{\mathrm{i}}$ in individual cells was monitored with an Olympus IX 51 inverted epifluorescence microscope and Slidebook software, using excitation wavelengths of 340 and $380 \mathrm{~nm}$ to detect Fura2/FuraCa fluorescence emission at $510 \mathrm{~nm}$ [28] .

\section{Statistical Analysis}


TRPC3/6/7 Knockdown Protects the Brain from Cerebral Ischemia Injury via Astrocyte Apoptosis Inhibiti... Page 7 of 36

Data are given as mean \pm standard deviation (S.D.). Student's $t$ test was used to compare between two groups. Statistical differences were considered significant when $P \quad 0.05$.

\section{Results}

Decreased Infarct Volume and Neurological Deficits in TRPC $3 / 6 / 7^{-/-}$Mice

To decipher the function of the $\mathrm{TRPC}_{3} / 6 / 7$ channels in cerebral I/R injury, we established the MCAO model with TRPC $3 / 6 / 7$ knockout mice and their wild-type control counterparts. Five consecutive TTC-stained coronal brain slices were arranged in cranial to caudal order (Fig. 2). The white brain area represents infracted brain tissue. The TRPC $3 / 6 / 7^{-/-}$group had smaller infarct volumes compared to the WT group ( $\left.\begin{array}{lll}P & 0.01, n & 5\end{array}\right)$. Sham groups showed no obvious infraction. Also, the neurological deficits were assessed $24 \mathrm{~h}$ after I/R. The neurological scores in the $\mathrm{TRPC}_{3} / 6 / 7^{-/-}$group were significantly reduced compared with those found in the WT group ( $P$ o.05, $n$ 5). Using this animal model system, we observed that (1) infarction volume (size) is reduced in $\mathrm{TRPC}_{3} / 6 / 7^{-1-}$ mice compared to that of WT mice and (2) motor behavior deficit is attenuated in $\mathrm{TRPC}_{3} / 6 / 7^{-/-}$mice.

A

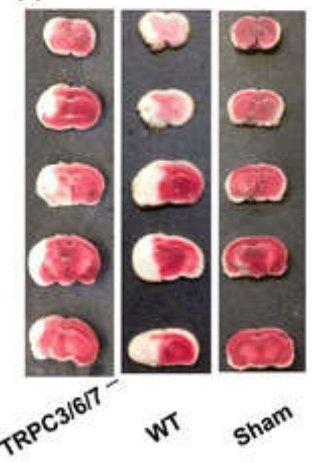

B

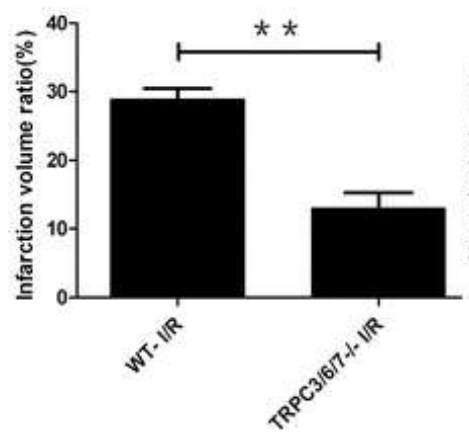

C

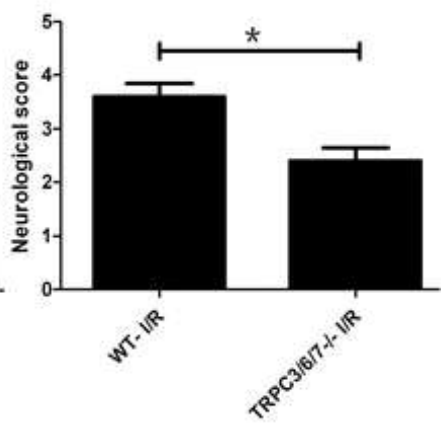

Fig.

Infarct volume is reduced and neurological deficits

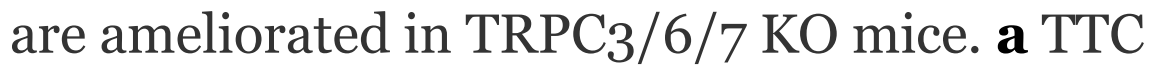

staining of the brain for each group. b The infarct

volume was measured using the ImageJ analysis

software. Values are expressed as mean \pm S.D.

( $n$ 5); $P$ o.01 between the WT group and 
$\mathrm{TRPC}_{3} / 6 / 7^{-/-}$group. c Evaluation of the neurological deficit was performed after occlusion of the MCA for $1 \mathrm{~h}$ followed by reperfusion for $24 \mathrm{~h}$. The values are expressed as mean \pm S.D. (n 5). $P$ O.05 WT group vs $\mathrm{TRPC}_{3} / 6 / 7^{-/-}$ group

Apoptosis of Primary Cultured Astrocytes Is Diminished in $\mathrm{TRPC}_{3} / 6 / 7^{-/-}$Mice

To test the impact of OGD-R on astrocyte apoptosis, astrocytes isolated from WT and $\mathrm{TRPC}_{3} / 6 / 7^{-/-}$mice were subjected to the OGD-R procedure, followed by FACS analysis. Cells appeared in the right upper and right lower quadrants of a dot plot represent all apoptotic cells. Percentage of apoptotic cells in the WT/OGD-R group was $60.4 \%$ (Fig. 3a). Compared to the WT/OGD-R group, astrocytes from the $\mathrm{TRPC}_{3} / 6 / 7^{-/-} /$OGD-R group exhibit a much lower apoptotic rate (36.7 \%, Fig. $3 \mathrm{a}$, b). To confirm this observation, cleaved caspase-3, a pro-apoptotic protein, was profiled by Western blot. As shown in Fig. 3 c, d, astrocytes from the TRPC $3 / 6 / 7^{-/-} /$OGD-R group demonstrated reduced cleaved caspase- 3 expression, compared to that in the WT/OGD-R group.

A

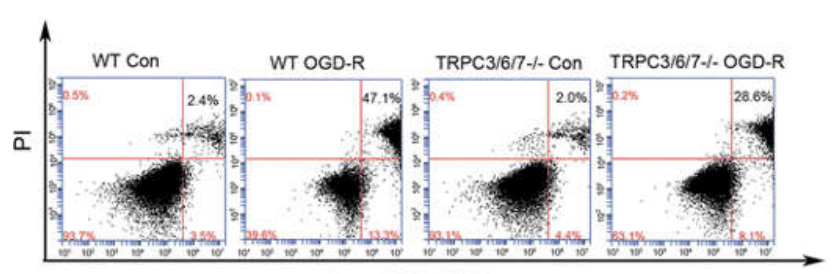

Annexin V FITC

C
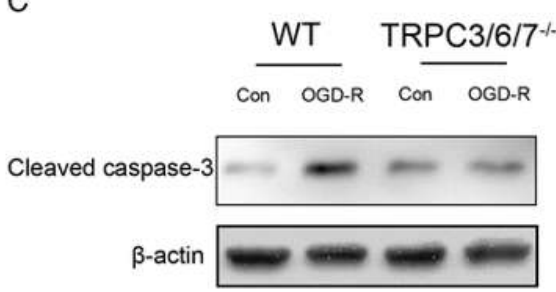

B

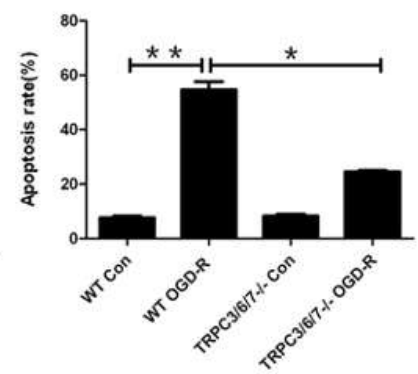

D

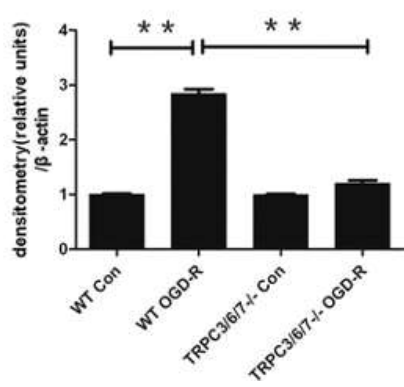

Fig. 
Decreased cell susceptibility to OGD-R in $\mathrm{TRPC}_{3} / 6 / 7^{-/-}$astrocytes. a WT and $\mathrm{TRPC}_{3} / 6 / 7^{-/-}$ cells were subjected or not to OGD-R, and their apoptotic status was analyzed by flow cytometry. $\mathbf{b}$ Data are shown as mean \pm S.D. $\left(\begin{array}{llll}n & 3\end{array}\right) . \quad P \quad 0.01$, $P \quad 0.05$ by two-tailed Student's $t$ test. c Western blot of cleaved caspase 3 expression. $\mathbf{d}$ Densitometry of cleaved caspase3, expression normalized with respect to actin of blots such as shown in c. Data are presented as mean \pm S.D. (n 3). $P$ O.01 between TRPC $3 / 6 / 7^{-/-}$OGD-R and WT OGD-R by two-tailed Student's $t$ test

Expression of Apoptosis-Related Proteins and mRNA Is Reduced by Loss of TRPC3/6/7 Channels both In Vivo and In Vitro

Bcl-2 and Bax belong to the Bcl-2 protein family; Bcl-2 promotes cell survival, whereas Bax accelerates apoptosis. In our in vitro study, Western blot analysis of astrocytes from the WT/OGD-R group showed that the expression level of proapoptotic Bax protein was significantly increased compared to the control group (Fig. $4 \mathrm{e}, \mathrm{f}$ ), but astrocytes from the TRPC $3 / 6 / 7^{-/-} / \mathrm{OGD}-\mathrm{R}$ group exhibited significantly diminished Bax expression (Fig. 4e, f). In contrast, expression of the anti-apoptotic protein Bcl-2 was reduced in astrocytes from the WT/OGD-R group (Fig. 4e, f) but enhanced in astrocytes from the TRPC $3 / 6 / 7^{-/-} /$OGD-R group (Fig. 4 e, f). mRNA levels of Bax and Bcl-2 in these groups of astrocytes showed expression profiles similar to the protein expression patterns (Fig. 4 h). Statistical analysis of the Bcl-2/Bax ratio, an index of anti-apoptosis, revealed that the OGD-R induced a dramatic reduction in the Bcl-2/Bax ratio in WT astrocytes and that such a reduction was ameliorated in TRPC3/6/7 KO cells (Fig. 4g). 

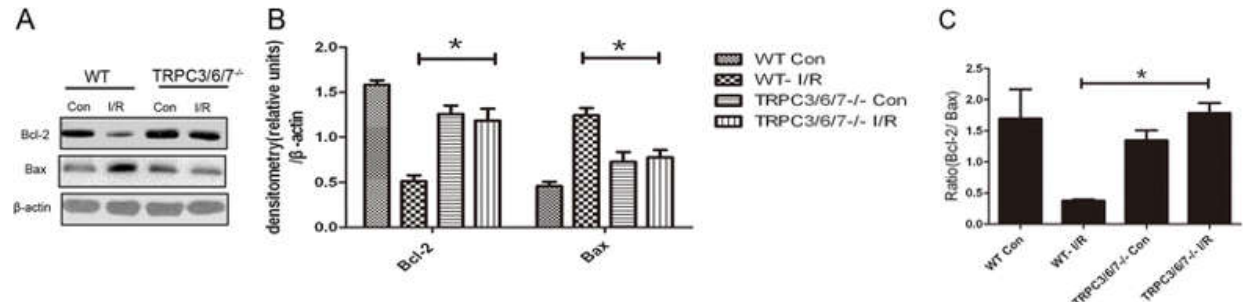

D
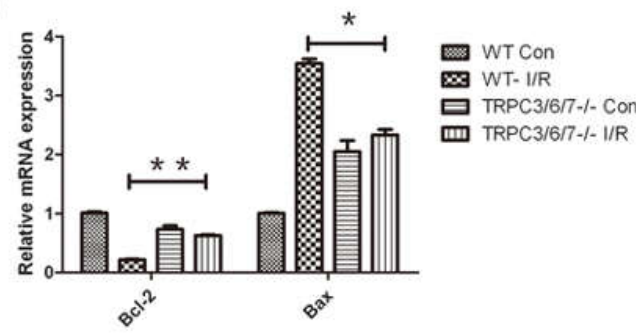

$\mathrm{E}$

$\mathrm{F}$
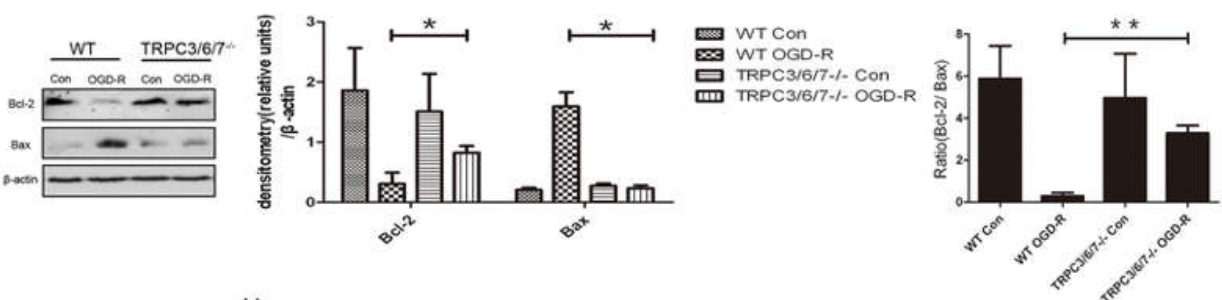

$\mathrm{H}$

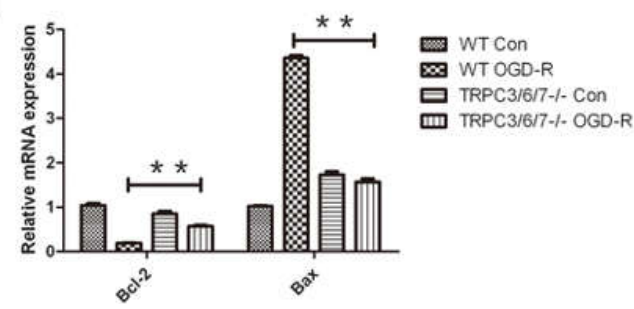

Fig.

Effect of TRPC3/6/7 ablation on MCAO and OGD-R induced changes in Bcl-2 and Bax expression. a Western blot of Bcl-2 and Bax expression. b Densitometry of Bax and Bcl-2, expression normalized with respect to actin of blots such as shown in a. Data are presented as mean \pm S.D. $(n$ 3). $P \quad 0.05$ between the TRPC $3 / 6 / 7^{-/-}$group and the WT group by twotailed Student's $t$ test. c Quantitation of Bcl-2/Bax data. $P$ 0.05, TRPC $3 / 6 / 7^{-/-} \mathrm{I} / \mathrm{R}$ injury model 
group compared to WT I/R injury model group. d Real-time PCR analysis of Bcl-2 and Bax relative mRNA expression. e Western blot of Bcl-2 and Bax expression. f Densitometry of Bax and Bcl-2, expression normalized with respect to actin of blots such as shown in e. Data are presented as means \pm S.D. $\left(\begin{array}{llll}n & 3\end{array}\right)$. $P \quad 0.05$ between $\mathrm{TRPC}_{3} / 6 / 7^{-/-}$OGD-R and WT OGD-R by twotailed Student's $t$ test. $\mathbf{g}$ Quantitation of data as Bcl-2/Bax ratios. $\quad P \quad 0.01, \mathrm{TRPC}_{3} / 6 / 7^{-/-}$ OGD-R compared to WT OGD-R. h Real-time PCR analysis of Bcl-2 and Bax relative mRNA expression

Western blot analysis of brain tissues from the MACO model demonstrated similar pattern changes of Bcl-2 and Bax. WT MCAO mice showed increased Bax expression and decreased Bcl-2 protein expression (protein in Fig. 4a, b; mRNA in Fig. 4d), whereas brain tissues from $\mathrm{TRPC}_{3} / 6 / 7^{-}$MACO mice exhibited a clear increase in Bcl-2 and unnoticeable changes in Bax. Also, the ratio of Bcl-2/Bax was visibly increased in the TRPC $3 / 6 / 7^{-7-}$ MACO mice, compared to WT MACO animals (Fig. $\underline{4})$.

p-AKT Levels Are Increased and p-NF-кB Levels Are Decreased in I/R-Subjected TRPC3/6/7 $7^{-/-}$Cells, both In Vivo and In Vitro

To determine the role of TRPC3/6/7 in AKT and NF- $\mathrm{KB}$ signaling following OGD-R treatment in astrocytes, we analyzed the protein levels of p-AKT and p-NF-кB. The OGD-R procedure increased NF- $\mathrm{KB}$ phosphorylation and decreased AKT phophorylation in WT astrocytes (Fig. $\underline{5}$ c, d). The MACO surgery generates similar results in WT animals (Fig. $\underline{5} \mathrm{a}, \mathrm{b}$ ). But in TRPC $3 / 6 / 7^{-1-}$ astrocytes, OGD-R induced marginal changes in NF-KB phosphorylation and increased AKT phophorylation. Similarly, MACO surgery also enhanced AKT phosphorylation in TRPC $3 / 6 / 7^{-1-}$ mouse brain tissues and did little to NF-кB phosphorylation (Fig. $\underline{5} \mathrm{a}, \mathrm{b}$ ). 
A

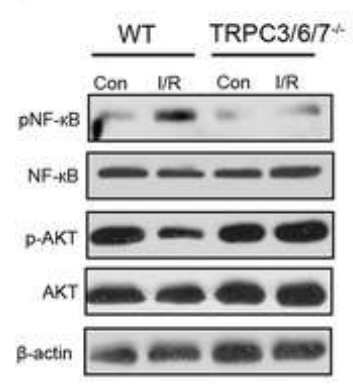

C

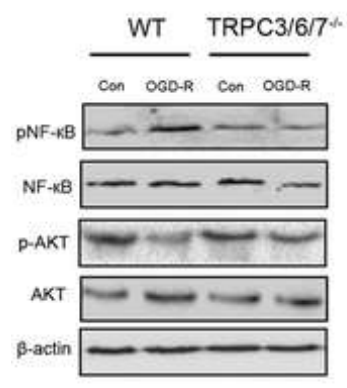

B

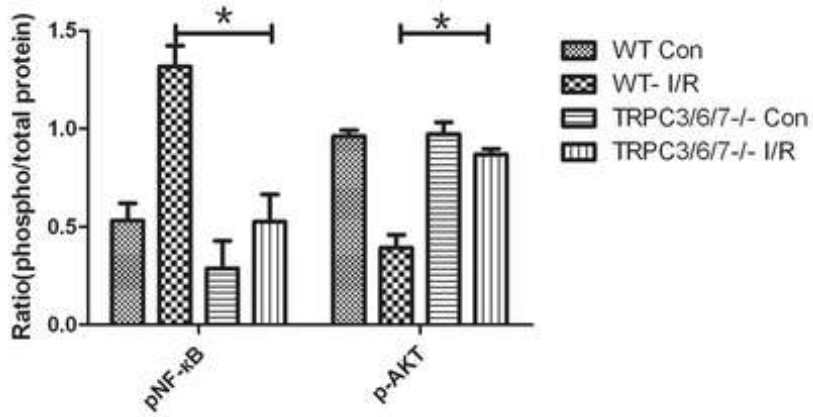

D

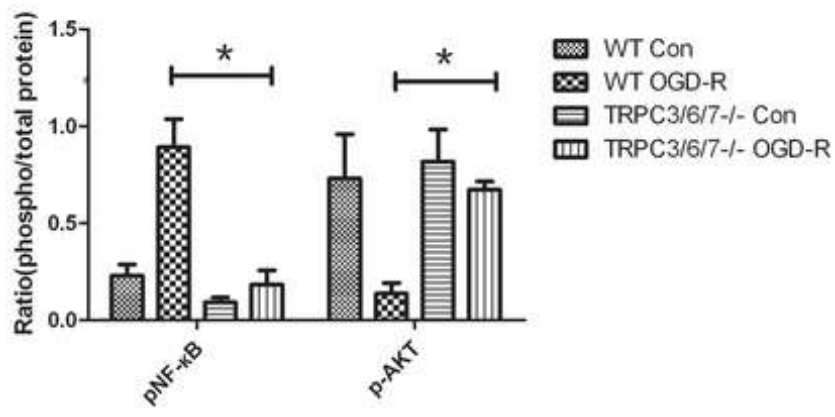

Fig.

Effect of TRPC3/6/7 on expression of p-NF-кB and p-AKT protein. a Western blot of p-NF-кB, p-AKT, total NF-кB, and total AKT, and of the corresponding $\beta$-actin, used as loading control. b Phosphoprotein levels as fraction of total. Data are presented as mean \pm S.D. $(n \quad 3) . \quad P \quad 0.05$ between TRPC3 $/ 6 / 7^{-/-}$I/R injury model and WT I/R injury model by two-tailed Student's $t$ test. c Western blot of p-NF-кB, p-ATK, total NF-кB, and total AKT, and of the corresponding $\beta$-actin, used as loading control. d Phosphoprotein levels as fraction of total. Data are presented as 


\section{mean \pm S.D. $(n \quad 3) . P \quad 0.05$ between $\mathrm{TRPC}_{3} / 6 / 7^{-/-}$OGD-R and WT OGD-R by two- tailed Student's $t$ test}

\section{Loss of TRPC3/6/7 Attenuated NF-кB Activation and Nuclear \\ Translocation Induced by OGD-R}

We investigated whether loss of TRPC $3 / 6 / 7$ could interfere with OGD-R-induced NF$\kappa \mathrm{B}$ activation and nuclear translocation. Nuclear translocation of $\mathrm{p} 65$ was detected by immunofluorescence staining. OGD-R promoted massive nuclear translocation of p65, a subunit of NF-KB in WT astrocytes (Fig. 6 ). But this translocation of p65 into nuclei was significantly compromised in TRPC $3 / 6 / 7^{-/-}$astrocytes upon OGD-R treatment (Fig. $\underline{6}$ ).

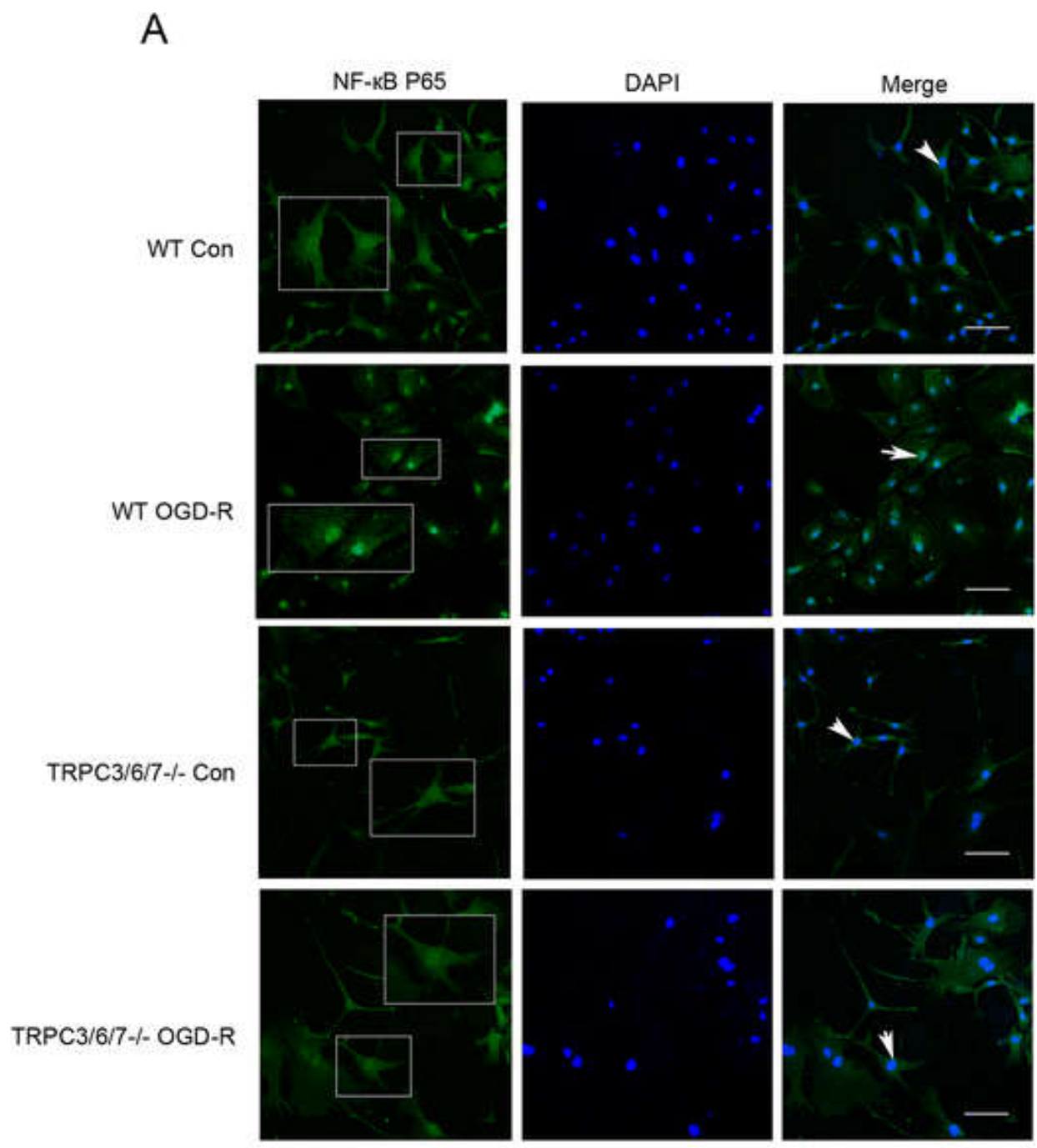




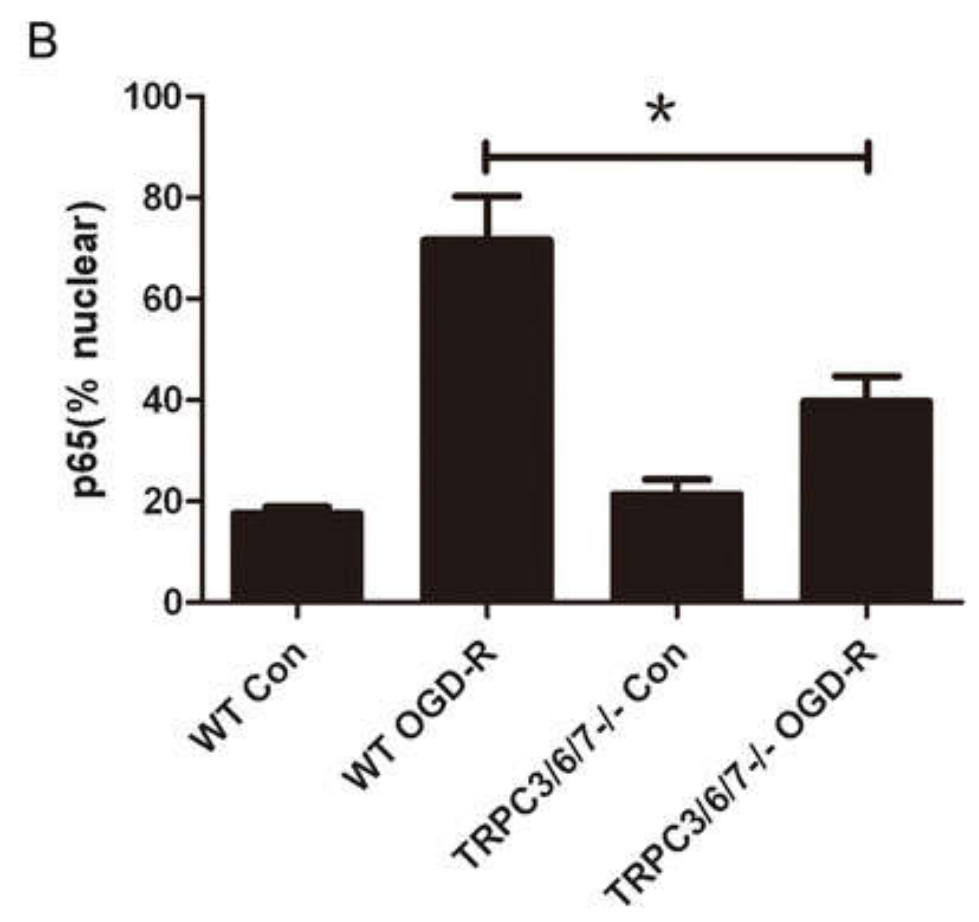

Fig.

OGD-R-induced alterations in cytoplasmicnuclear distribution of the p65 subunit of NF-кB in astrocytes. Cells were pretreated with vehicle or in OGD-R condition and analyzed by immunofluorescence microscopy to determine cells with p65 (green fluorescence) subunit present within their nuclei (labeled with DAPI, blue fluorescence). a OGD-R increased the trafficking of the p65 subunit of NF- $\mathrm{KB}$ into the nucleus. The arrowhead indicated p65 subunit of NF-кB in the nucleus. Scale bar: $50 \mu \mathrm{m}$. b Quantification of the p65 subunit of NF- $\mathrm{KB}$ in the nucleus, positive cells of total cells in each region. 
The p65 subunit of NF- $\mathrm{KB}$ in the nucleus decreased in TRPC3/6/7 ${ }^{-1-}$ OGD-R compared to WT OGD-R, $P \quad 0.05$

TRPC3/6/7 Participates in $\mathrm{Ca}^{2+}$ Release and $\mathrm{Ca}^{2+}$ Influx in Astrocytes Induced by OGD-R

The effect of the OGD-R procedure on SOCE in WT and TRPC $3 / 6 / 7^{-/-}$astroctyes was examined using ratiometric fluorescence video microscopy of Fura2-loaded cells as described previously $[\underline{29}, \underline{30}, \underline{31}]$. By comparing the second peaks of each trace, which represents the influx of free calcium into cells, we observed that the ER SERCA pump inhibitor thapsigargin induced a SOCE that is significantly lower in OGD-Rtreated $\mathrm{TRPC}_{3} / 6 / 7 \mathrm{KO}$ astrocytes than that in OGD-R-treated WT astrocytes ( $\left.\begin{array}{ll}P & 0.01\end{array}\right)$ (Fig. 7). This observation implies that TRPC $3 / 6 / 7$ channels participate in the OGD-R-induced calcium influx in astrocytes.

A

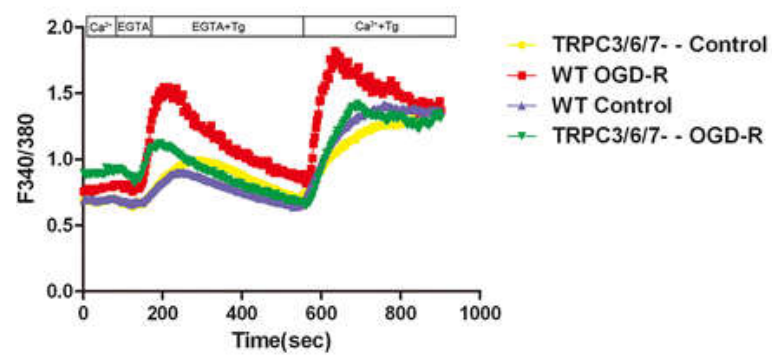

B

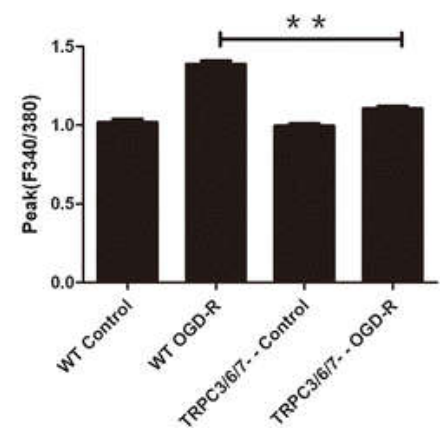

Fig.

OGD-R increased, and ablation of TRPC $3 / 6 / 7$ prevented the OGD-R-induced increase of Tginduced SOCE in primary astroctyes. a Time course of Tg-induced intracellular $\mathrm{Ca}^{2+}$ changes (intracellular $\mathrm{Ca}^{2+}$ was monitored with the Fura2 $\mathrm{Ca}^{2+}$ sensitive fluorescent dye). b Peak $340 / 380$ ratios $P$ 0.01, TRPC3/6/7 KO astrocytes compared to WT astrocytes 


\section{Discussion}

Stroke triggers a complex cascade of pathophysiologic events in the brain that ultimately lead to cell death and infarction. Several molecular pathways are involved, such as calcium overload, oxidative stress, excitotoxicity, and apoptotic-like cell death. The abovementioned processes interact with each other and form a complex regulatory network. Calcium overload is an important mechanism of cerebral ischemia and reperfusion injury.

The past decade has been a period of rapid development in stroke research. Several different mechanisms have been implicated in ischemia-induced cell death, including excitotoxicity, oxidative stress, and inflammation, apoptosis, and cell death. In the process of cell death, intracellular accumulation of $\mathrm{Ca}^{2+}$ plays an important role. Past studies have provided ample of evidence indicating that glutamate receptors are the major trigger for $\mathrm{Ca}^{2+}$ influx in neurons following stroke. Recently, TRP channels have been shown to regulate $\mathrm{Ca}^{2+}$ homeostasis and to be involved in pathophysiology of stroke $[\underline{6}, \underline{7}, \underline{8}]$.

The mammalian TRP channel superfamily has approximately 30 members that are grouped into six subfamilies: TRPA, TRPC, TRPM, TRPML, TRPP, and TRPV. These channels are widely expressed in all cell types and tissues, They play a critical role in many cellular processes by changing cytosolic free $\mathrm{Ca}^{2+}$ concentrations [32]. TRPC channels are highly expressed in some regions of the brain. Within the seven members of the TRPC family (TRPC1-7), TRPC1 forms heteromers with TRPC4 or TRPC5. Similarly, TRPC3, TRPC6, and TRPC7 coassociate to form heteromers [풀.

For decades, cerebral ischemia research was mainly focused on neuronal cells. It is a rather recent concept that astrocytes play significant roles in the demise of brain tissue after cerebral ischemia, in addition to protecting brain function and enhancing survival and regeneration under these conditions [요 12]. Subtle and temporal regulation of astrocyte functions after stroke will undoubtedly impact the survival of

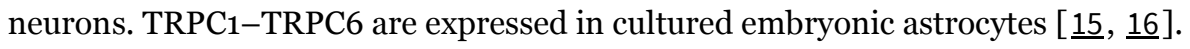
The present study was designed to elucidate the role of the TRPC $3 / 6 / 7$ group of TRPC channels in brain ischemic injury, focusing on astrocytes in cerebral ischemia reperfusion injury.

To decipher the function of TRPC $3 / 6 / 7$ subfamily in cerebral ischemia/reperfusion injury in vivo, we established middle cerebral artery occlusion (MCAO)/reperfusion model with TRPC $3 / 6 / 7$ knockout mice and wild-type control mice. Using this animal model system, we found that (1) infarction volume (size) is reduced in $\mathrm{TRPC}_{3} / 6 / 7$ KO mice compared to that in WT mice and (2) motor behavior deficit is ameliorated in TRPC $3 / 6 / 7$ KO mice. Western blot analysis revealed that MCAO followed by reperfusion enhances the phosphorylation status of NF-кB and decreases that of AKT, increases Bax expression, and reduces Bcl-2 levels in cerebral cortex of WT 
mice as seen $24 \mathrm{~h}$ after reperfusion. In contrast to WT mice, these changes were blunted in $\mathrm{TRPC}_{3} / 6 / 7^{-/-}$mice $\left(\begin{array}{ll}P & 0.05\end{array}\right)$. The Bcl-2/Bax ratio was elevated $24 \mathrm{~h}$ after reperfusion in $\mathrm{TRPC}_{3} / 6 / 7 \mathrm{KO}$ mice compared to WT mice.

To investigate whether the protection afforded by loss of TRPC $3 / 6 / 7$ cerebral ischemia injury is associated with parallel changes in astrocytes, we next studied primary astrocytes isolated from both KO and WT mice and subjected to OGD-R (mimicking the ischemia/reperfusion situation). Western blot analysis showed that the OGD-R protocol enhances the phosphorylation status of NF- $\mathrm{KB}$, increases Bax expression, and reduces Bcl-2 levels in astrocytes from WT mice. In contrast, the absence of TRPC3/6/7 markedly prevented the OGD-R-induced upregulation of phosphorylation status of NF- $\mathrm{KB}$, the increase in Bax levels, and the decrease in Bcl-2 levels ( $\left.\begin{array}{ll}P & 0.05\end{array}\right)$. Loss of TRPC $3 / 6 / 7$ prevented much of the OGD-R-induced apoptosis in astrocytes. These findings provide the evidence that loss of TRPC $3 / 6 / 7$ has neuroprotective activity on cerebral ischemia/reperfusion injury, and this effect may be attributable to an anti-apoptotic effect via inhibition of NF-кB phosphorylation and promotion of AKT phosphorylation.

The TRPC family proteins can be responsible for SOCE and ROCE in a variety of cell types [34]. According to recent findings, $\mathrm{Ca}^{2+}$ entry through receptor-operated $\mathrm{Ca}^{2+}$ channels (ROCs) and store-operated $\mathrm{Ca}^{2+}$ channels (SOCs) contributes to shape cytoplasmic $\mathrm{Ca}^{2+}$ signals in astrocytes $[\underline{15}, \underline{17}, \underline{35}]$.

Astrocytes can remove glutamate from the synaptic cleft and thereby prevent Gluinduced excitotoxicity and associated elevations in intracellular $\mathrm{Ca}^{2+}$ due to activation of metabotropic glutamate receptors. These cells thus play an active, central role in brain physiology [ $\underline{36}]$.

Although several members of the TRPC family of channels have been shown to play roles in astrocytic $\mathrm{Ca}^{2+}$ responses by acting as $\mathrm{Ca}^{2+}$ entry pathways across the plasma membrane $[\underline{16}, \underline{19}, \underline{37}, \underline{38}]$, there are only a few reports revealing the relationship between the physiological and pathophysiological functions of astrocytes and TRPC channel-mediated $\mathrm{Ca}^{2+}$ entry. Supporting a role for the TRPC channel in astrocyteassociated dysfunctions of the brain, the pro-inflammatory cytokine IL-1 can cause TRPC6-dependent changes in $\left[\mathrm{Ca}^{2+}\right]_{\mathrm{i}}$ in mouse astrocytes $[\underline{18}, \underline{19}]$. Shirakawa [ $\left.\underline{18}\right]$ found that selective inhibition of $\mathrm{TRPC}_{3}$ attenuated thrombin-induced $\mathrm{Ca}^{2+}$ responses and consequent cellular responses in cultured cortical rat astrocytes.

In our studies, we examined SOCE in primary astrocytes isolated from both KO and WT mice. Using Fura2 to monitor intracellular calcium changes, we observed that Tg-induced SOCE in astrocytes subjected to OGD-R is significantly higher than in control astrocytes and that this increase is absent in TRPC $3 / 6 / 7 \mathrm{KO}$ astrocytes ( $\left.\begin{array}{ll}P & 0.01\end{array}\right)$. This adds to the list of finding that relates TRPC channels to astrocyte function.

Cerebral I/R triggers several molecular mechanisms including apoptosis and causes irreversible damages to cerebral tissues including astrocytes, and we hypothesized, $\mathrm{TRPC}_{3}, \mathrm{C} 6$, and/or $\mathrm{C}_{7}$ could participate in this pathological process. If so, ablation of 
these channels should reduce the infarct size and cell apoptosis and decrease astrocyte apoptosis in vitro. This we found. We looked into the underlying mechanisms of $\mathrm{TRPC}_{3} / 6 / 7$ ablation associated with astrocyte protection in cerebral I/R, which had not been studied previously. Astrocytes are the most numerous cell type in the higher mammalian nervous system. They play key roles in modulate synaptic activity and structural, trophic, and metabolic support to neurons. Accordingly, impairment of astrocyte functions during brain ischemia and other insults are likely to influence neuronal survival and plasticity [39]. AKT and Bcl-2 play vital roles in regulating the intracellular apoptotic signaling pathways. The $\mathrm{PI} 3 \mathrm{~K} / \mathrm{AKT}$ signaling system is an upstream mediator of the Bcl-2 protein family. AKT phosphorylates Bad to suppress apoptosis, which then inactivates its inhibitory effects on the anti-apoptotic protein Bcl-2 and eventually inhibits the release of cytochrome c [ $\underline{40}]$. However, the level of p-AKT protein is decreased after cerebral I/R injury, implying a decrease of anti-apoptotic activity in the brain [41]. Indeed, enhancing phosphorylation of AKT and Bcl-2 expression or preventing downregulation of Bcl-2 is beneficial in cerebral I/R or stroke situations [42]. In the present study, increased tissue p-AKT and Bcl-2 in TRPC3/6/7 KO mice probably accounts for the improved neurological deficit scores and reduced infarction volume. Bcl-2 and p-AKT expression were also upregulated in $\mathrm{TRPC}_{3} / 6 / 7^{-/-}$astrocytes upon OGD-R treatment in vitro. Our data imply that removal of TRPC $3 / 6 / 7$ attenuates astrocyte apoptosis probably by increasing the phosphorylation status of AKT and hence activating Bcl-2 expression.

NF-кB plays an important role in TRPC expression in many cell types. Tiruppathi showed that tumor necrosis factor (TNF) induces the NF-кB-dependent upregulation of TRPC1 in human umbilical vein endothelial cells (HUVECs) [43]. Thrombininduced TRPC1 upregulation in HUVECs was due to the increase of NF-кB transcriptional activity by $\mathrm{Ca}^{2+}$ signaling in a feedforward manner and subsequent protein kinase C (PKC) activation [44]. TRPC3 is involved in astrogliosis after stroke. It has been shown that thrombin can initiate astrogliosis in cultured rat and human astrocytes and upregulate TRPC3 expression via nuclear factor-кB, extracellular signal-regulated protein kinase (ERK), protease-activated receptor 1 (PAR-1), and c-JunNH2-terminal kinase signaling pathways [1ㅗ, $\underline{38}]$. We observed in this study that ischemia/reperfusion enhanced NF- $\mathrm{KB}$ phosphorylation and nuclear translocation in WT astrocytes, whereas TRPC $3 / 6 / 7$ deletion diminishes these NF-кB changes. Also these NF-кB changes are positively correlated with astrocyte apoptosis. Whether and how NF-кB activation regulates astrocyte apoptosis remains to be determined in the future studies.

Our results showed that disruption of $\mathrm{TRPC}_{3} / 6 / 7$ subgroup of TRPC channels exerts a major protective effect against cerebral injury initiated by ischemia/reperfusion in mice, at least at the level of astrocytes during the cerebral ischemic process. In conclusion, astrocyte apoptosis was a major injury in cerebral I/R injury. Disruption of the TRPC $3 / 6 / 7$ could reduce the apoptosis of astrocytes in cerebral I/R injury. The recovered astrocytes provided helpful repairing conditions thus accelerating the recovery of insulted brain functions. Therefore, a TRPC-directed intervention offers great promise for recovery therapies of cerebral ischemia in patient after stroke. 


\section{Notes}

\section{Acknowledgments}

This research was supported by National Natural Science Foundation of China (Grant 31171087 and Grant 30970662 to YH Liao), and NIH intramural Research Program (Project 01-ES-101684 to LB).

\section{Compliance with Ethical Standards}

Animals were treated in compliance with the Guide for the Care and Use of Laboratory Animals (National Academy of Science). All animal studies were approved by the Animal Care and Utilization Committee of Huazhong University of Science and Technology.

\section{References}

1 Kelly PJ, Morrow JD, Ning M, Koroshetz W, Lo EH, Terry E, Milne GL, Hubbard $J$ et al (2008) Oxidative stress and matrix metalloproteinase-9 in acute ischemic stroke: the biomarker evaluation for antioxidant therapies in stroke (BEAT-stroke) study. Stroke 39(1):100-104. doi: 10.1161/STROKEAHA.107.488189 (https://doiorg.ezproxy.nihlibrary.nih.gov/10.1161/STROKEAHA.107.488189) CrossRef (https://doiorg.ezproxy.nihlibrary.nih.gov/10.1161/STROKEAHA.107.488189) PubMed (http://www-ncbi-nlm-nihgov.ezproxy.nihlibrary.nih.gov/entrez/query.fcgi cmd Retrieve db PubMed dopt Abstract list uids 18063832) Google Scholar (http://scholar.google.com.ezproxy.nihlibrary.nih.gov/scholar lookup title Oxidative\%20stress\%20and\%20matrix\%20metalloproteinase-9\%20in\% 20acute\%2oischemic\%20stroke\%3A\%20the\%2obiomarker\%2oevaluation\% 2ofor\%20antioxidant\%2otherapies\%2oin\%2ostroke\%20\%28BEAT-stroke\% 29\%20study author PJ.\%20Kelly author JD.\%20Morrow author M.\% 20Ning author W.\%20Koroshetz author EH.\%20Lo author E.\% 20Terry author GL.\%20Milne author J.\% 20Hubbard journal Stroke volume 39 issue 1 pages 100104 publication year 2008 doi 10.1161\%2FSTROKEAHA.107.488189)

2 Dirnagl U, Iadecola C, Moskowitz MA (1999) Pathobiology of ischaemic stroke: an integrated view. Trends Neurosci 22(9):391-397. doi: 10.1016/So166-2236(99)01401-o (https://doiorg.ezproxy.nihlibrary.nih.gov/10.1016/So166-2236(99)01401-0)

3 Mergenthaler P, Dirnagl U, Meisel A (2004) Pathophysiology of stroke: lessons from animal models. Metab Brain Dis 19(3-4):151-167 
CrossRef (https://doi-org.ezproxy.nihlibrary.nih.gov/10.1023/B\%

3AMEBR.0000043966.46964.e6)

PubMed (http://www-ncbi-nlm-nih-

gov.ezproxy.nihlibrary.nih.gov/entrez/query.fcgi

cmd Retrieve db PubMed dopt Abstract list uids 15554412)

Google Scholar

(http://scholar.google.com.ezproxy.nihlibrary.nih.gov/scholar lookup

title Pathophysiology\%20of\%20stroke\%3A\%2olessons\%2ofrom\%

20animal\%20models author P.\%20Mergenthaler author U.\%

20Dirnagl author A.\%20Meisel journal Metab\%2oBrain\%

20Dis volume 19 issue $3 \% \mathrm{E} 2 \% 80 \% 934$ pages 151 -

167 publication year 2004)

4 PH C (2001) Reactive oxygen radicals in signaling and damage in the ischemic brain. J Cereb Blood Flow Metab 21(1):2-14.

doi: 10.1097/00004647-200101000-00002 (https://doi-

org.ezproxy.nihlibrary.nih.gov/10.1097/00004647-200101000-00002)

CrossRef (https://doi-org.ezproxy.nihlibrary.nih.gov/10.1097/00004647-

200101000-00002)

Google Scholar

(http://scholar.google.com.ezproxy.nihlibrary.nih.gov/scholar lookup

title Reactive\%20oxygen\%2oradicals\%20in\%20signaling\%20and\%

2odamage\%2oin\%2othe\%2oischemic\%2obrain author C.\%

20PH journal J\%20Cereb\%2oBlood\%2oFlow\%

20Metab volume 21 issue 1 pages 2-14 publication year 2001 doi 10

$.1097 \% 2 F 00004647-200101000-00002)$

5 Stork CJ, Li YV (2006) Intracellular zinc elevation measured with a "calciumspecific" indicator during ischemia and reperfusion in rat hippocampus: a question on calcium overload. J Neurosci 26(41):10430-10437.

doi: 10.1523/JNEUROSCI.1588-06.2006 (https://doi-

org.ezproxy.nihlibrary.nih.gov/10.1523/JNEUROSCI.1588-06.2006)

CrossRef (https://doi-

org.ezproxy.nihlibrary.nih.gov/10.1523/JNEUROSCI.1588-06.2006)

PubMed (http://www-ncbi-nlm-nih-

gov.ezproxy.nihlibrary.nih.gov/entrez/query.fcgi

cmd Retrieve db PubMed dopt Abstract list uids 17035527)

Google Scholar

(http://scholar.google.com.ezproxy.nihlibrary.nih.gov/scholar lookup

title Intracellular\%20zinc\%2oelevation\%20measured\%20with\%20a\%20\%

E2\%80\%9Ccalcium-specific\%E2\%80\%9D\%20indicator\%20during\%

2oischemia\%2oand\%2oreperfusion\%2oin\%2orat\%2ohippocampus\%3A\%

20a\%20question\%20on\%20calcium\%20overload author CJ.\%

20Stork author YV.\%20Li journal J\%

20Neurosci volume 26 issue 41 pages 10430-

10437 publication year 2006 doi 10.1523\%2FJNEUROSCI.1588-

06.2006)

6 Xiong XY, Wang J, Qian M, Yang QW (2014) Iron and intracerebral hemorrhage: from mechanism to translation. Transl Stroke Res 5(4):429

-441. doi: 10.1007/s12975-013-0317-7 (https://doi-

org.ezproxy.nihlibrary.nih.gov/10.1007/s12975-013-0317-7) 
CrossRef (https://doi-org.ezproxy.nihlibrary.nih.gov/10.1007/s12975-013-

0317-7)

PubMed (http://www-ncbi-nlm-nih-

gov.ezproxy.nihlibrary.nih.gov/entrez/query.fcgi

cmd Retrieve db PubMed dopt Abstract list uids 24362931)

Google Scholar

(http://scholar.google.com.ezproxy.nihlibrary.nih.gov/scholar lookup

title Iron\%20and\%2ointracerebral\%20hemorrhage\%3A\%20from\%

20mechanism\%20to\%20translation author XY.\%20Xiong author J.\%

20Wang author M.\%20Qian author QW.\%20Yang journal Transl\%

20Stroke\%2oRes volume 5 issue 4 pages 429-

441 publication year 2014 doi 10.1007\%2Fs12975-013-0317-7)

7 Song M, Yu SP (2014) Ionic regulation of cell volume changes and cell death after ischemic stroke. Transl Stroke Res 5(1):17-27. doi: 10.1007/s12975-0130314-x (https://doi-org.ezproxy.nihlibrary.nih.gov/10.1007/s12975-0130314-x)

CrossRef (https://doi-org.ezproxy.nihlibrary.nih.gov/10.1007/s12975-0130314-x)

PubMed (http://www-ncbi-nlm-nihgov.ezproxy.nihlibrary.nih.gov/entrez/query.fcgi

cmd Retrieve db PubMed dopt Abstract list uids 24323733)

Google Scholar

(http://scholar.google.com.ezproxy.nihlibrary.nih.gov/scholar lookup

title Ionic\%2oregulation\%20of\%20cell\%20volume\%2ochanges\%20and\%

20cell\%2odeath\%2Oafter\%2oischemic\%20stroke author M.\%

20Song author SP.\%20Yu journal Transl\%20Stroke\%

20Res volume 5 issue 1 pages 17-

27 publication year 2014 doi 10.1007\%2Fs12975-013-0314-x)

8 Chen D, Yu SP, Wei L (2014) Ion channels in regulation of neuronal regenerative activities. Transl Stroke Res 5(1):156-162. doi: 10.1007/s12975013-0320-z (https://doi-org.ezproxy.nihlibrary.nih.gov/10.1007/s12975-

013-0320-z)

CrossRef (https://doi-org.ezproxy.nihlibrary.nih.gov/10.1007/s12975-013-

O320-z)

PubMed (http://www-ncbi-nlm-nih-

gov.ezproxy.nihlibrary.nih.gov/entrez/query.fcgi

cmd Retrieve db PubMed dopt Abstract list uids 24399572)

PubMedCentral (http://www-ncbi-nlm-nih-

gov.ezproxy.nihlibrary.nih.gov/pmc/articles/PMC3961762)

Google Scholar

(http://scholar.google.com.ezproxy.nihlibrary.nih.gov/scholar lookup

title Ion\%2ochannels\%2oin\%2oregulation\%20of\%2oneuronal\%

2oregenerative\%20activities author D.\%20Chen author SP.\%

$20 Y u$ author L.\%20Wei journal Transl\%20Stroke\%

20Res volume 5 issue 1 pages 156 -

162 publication year 2014 doi 10.1007\%2Fs12975-013-O320-z)

9 Swanson RA, Ying W, Kauppinen TM (2004) Astrocyte influences on ischemic neuronal death. Curr Mol Med 4(2):193-205.

doi: $10.2174 / 1566524043479185$ (https://doi-

org.ezproxy.nihlibrary.nih.gov/10.2174/1566524043479185) 
CrossRef (https://doi-

org.ezproxy.nihlibrary.nih.gov/10.2174/1566524043479185)

PubMed (http://www-ncbi-nlm-nih-

gov.ezproxy.nihlibrary.nih.gov/entrez/query.fcgi

cmd Retrieve db PubMed dopt Abstract list uids 15032713)

Google Scholar

(http://scholar.google.com.ezproxy.nihlibrary.nih.gov/scholar lookup

title Astrocyte\%2oinfluences\%20on\%20ischemic\%2oneuronal\%

20death author RA.\%20Swanson author W.\%20Ying author TM.\%

20Kauppinen journal Curr\%20Mol\%

2oMed volume 4 issue 2 pages $193^{-}$

205 publication year 2004 doi 10.2174\%2F1566524043479185)

10 Ouyang YB, Voloboueva LA, Xu LJ, Giffard RG (2007) Selective dysfunction of hippocampal CA1 astrocytes contributes to delayed neuronal damage after transient forebrain ischemia. J Neurosci 27(16):4253-4260.

doi: 10.1523/JNEUROSCI.0211-07.2007 (https://doi-

org.ezproxy.nihlibrary.nih.gov/10.1523/JNEUROSCI.0211-07.2007)

CrossRef (https://doi-

org.ezproxy.nihlibrary.nih.gov/10.1523/JNEUROSCI.0211-07.2007)

PubMed (http://www-ncbi-nlm-nih-

gov.ezproxy.nihlibrary.nih.gov/entrez/query.fcgi

cmd Retrieve db PubMed dopt Abstract list uids 17442809)

PubMedCentral (http://www-ncbi-nlm-nih-

gov.ezproxy.nihlibrary.nih.gov/pme/articles/PMC3140959)

Google Scholar

(http://scholar.google.com.ezproxy.nihlibrary.nih.gov/scholar lookup

title Selective\%20dysfunction\%20of\%2ohippocampal\%20CA1\%

20astrocytes\%20contributes\%20to\%2odelayed\%2oneuronal\%20damage\%

20after\%20transient\%2oforebrain\%20ischemia author YB.\%

20Ouyang author LA.\%20Voloboueva author LJ.\%20Xu author RG.\%

20Giffard journal J\%20Neurosci volume 27 issue 16 pages 4253-

4260 publication year 2007 doi 10.1523\%2FJNEUROSCI.0211-07.2007)

11 Xu L, Emery JF, Ouyang YB, Voloboueva LA, Giffard RG (2010) Astrocyte targeted overexpression of Hsp72 or SOD2 reduces neuronal vulnerability to forebrain ischemia. Glia 58(9):1042-1049. doi: 10.1002/glia.20985

(https://doi-org.ezproxy.nihlibrary.nih.gov/10.1002/glia.20985)

CrossRef (https://doi-org.ezproxy.nihlibrary.nih.gov/10.1002/glia.20985)

PubMed (http://www-ncbi-nlm-nih-

gov.ezproxy.nihlibrary.nih.gov/entrez/query.fcgi

cmd Retrieve db PubMed dopt Abstract list uids 20235222)

PubMedCentral (http://www-ncbi-nlm-nih-

gov.ezproxy.nihlibrary.nih.gov/pmc/articles/PMC3108566)

Google Scholar

(http://scholar.google.com.ezproxy.nihlibrary.nih.gov/scholar lookup

title Astrocyte\%2Otargeted\%2Ooverexpression\%20of\%20Hsp72\%20or\%

20SOD2\%2oreduces\%2oneuronal\%2ovulnerability\%2oto\%2oforebrain\%

20ischemia author L.\%20Xu author JF.\%20Emery author YB.\%

20Ouyang author LA.\%20Voloboueva author RG.\%

20Giffard journal Glia volume 58 issue 9 pages 1042-

1049 publication year 2010 doi 10.1002\%2Fglia.20985)

https://link-springer-com.ezproxy.nihlibrary.nih.gov/article/10.1007\%2Fs12035-016-0227-2 
12 Anderson MF, Blomstrand F, Blomstrand C, Eriksson PS, Nilsson M (2003) Astrocytes and stroke: networking for survival Neurochem Res 28(2):293

$-305$

CrossRef (https://doi-org.ezproxy.nihlibrary.nih.gov/10.1023/A\%

3A1022385402197)

PubMed (http://www-ncbi-nlm-nih-

gov.ezproxy.nihlibrary.nih.gov/entrez/query.fcgi

cmd Retrieve db PubMed dopt Abstract list uids 12608702)

Google Scholar

(http://scholar.google.com.ezproxy.nihlibrary.nih.gov/scholar lookup

title Astrocytes\%20and\%20stroke\%3A\%2onetworking\%2ofor\%20survival\% $3 \mathrm{~F}$ author MF.\%20Anderson author F.\%20Blomstrand author C.\%

20Blomstrand author PS.\%20Eriksson author M.\%

20Nilsson journal Neurochem\%2oRes volume 28 issue 2 pages 293-

305 publication year 2003)

13 han X, Ander BP, Liao IH, Hansen JE, Kim C, Clements D, Weisbart RH, Nishimura RN et al (2010) Recombinant Fv-Hsp70 protein mediates neuroprotection after focal cerebral ischemia in rats. Stroke 41(3):538-543. doi: 10.1161/STROKEAHA.109.572537 (https://doi-

org.ezproxy.nihlibrary.nih.gov/10.1161/STROKEAHA.109.572537)

CrossRef (https://doi-

org.ezproxy.nihlibrary.nih.gov/10.1161/STROKEAHA.109.572537)

PubMed (http://www-ncbi-nlm-nih-

gov.ezproxy.nihlibrary.nih.gov/entrez/query.fcgi

cmd Retrieve db PubMed dopt Abstract list uids 20075343)

PubMedCentral (http://www-ncbi-nlm-nih-

gov.ezproxy.nihlibrary.nih.gov/pmc/articles/PMC2957177)

Google Scholar

(http://scholar.google.com.ezproxy.nihlibrary.nih.gov/scholar lookup

title Recombinant\%20Fv-Hsp70\%20protein\%20mediates\%

2oneuroprotection\%20after\%2ofocal\%20cerebral\%2oischemia\%2oin\%

2orats author X.\%2O han author BP.\%20Ander author IH.\%

20 Liao author JE.\%20Hansen author C.\%20Kim author D.\%

20Clements author RH.\%2OWeisbart author RN.\%

20Nishimura journal Stroke volume 41 issue 3 pages 538-

543 publication year 2010 doi 10.1161\%2FSTROKEAHA.109.572537)

14 Birnbaumer L (2009) The TRPC class of ion channels: a critical review of

their roles in slow, sustained increases in intracellular $\mathrm{Ca}(2+)$ concentrations. Annu Rev Pharmacol Toxicol 49:395-426.

doi: 10.1146/annurev.pharmtox.48.113006.094928 (https://doi-

org.ezproxy.nihlibrary.nih.gov/10.1146/annurev.pharmtox.48.113006.09492

8)

CrossRef (https://doi-

org.ezproxy.nihlibrary.nih.gov/10.1146/annurev.pharmtox.48.113006.09492

8)

PubMed (http://www-ncbi-nlm-nih-

gov.ezproxy.nihlibrary.nih.gov/entrez/query.fcgi

cmd Retrieve db PubMed dopt Abstract list uids 19281310)

Google Scholar

(http://scholar.google.com.ezproxy.nihlibrary.nih.gov/scholar lookup 
title The\%20TRPC\%20class\%20of\%2oion\%20channels\%3A\%20a\% 20critical\%2oreview\%20of\%20their\%2oroles\%2oin\%2oslow\%2C\% 2osustained\%2oincreases\%2oin\%2ointracellular\%20Ca\%282\%2B\%29\% 2oconcentrations author L.\%20Birnbaumer journal Annu\%20Rev\% 20Pharmacol\%20Toxicol volume 49 pages 395426 publication year 2009 doi $10.1146 \%$ 2Fannurev.pharmtox.48.113006.094928)

15 Pizzo P, Burgo A, Pozzan T, Fasolato C (2001) Role of capacitative calcium entry on glutamate-induced calcium influx in type-I rat cortical astrocytes. $\mathrm{J}$ Neurochem 79(1):98-109. doi: 10.1046/j.1471-4159.2001.00539.x (https://doi-org.ezproxy.nihlibrary.nih.gov/10.1046/j.14714159.2001.00539.x) CrossRef (https://doi-org.ezproxy.nihlibrary.nih.gov/10.1046/j.14714159.2001.00539.x) PubMed (http://www-ncbi-nlm-nihgov.ezproxy.nihlibrary.nih.gov/entrez/query.fcgi cmd Retrieve db PubMed dopt Abstract list uids 11595762)

Google Scholar (http://scholar.google.com.ezproxy.nihlibrary.nih.gov/scholar lookup title Role\%20of\%2ocapacitative\%20calcium\%20entry\%20on\%2oglutamateinduced\%20calcium\%2oinflux\%20in\%2otype-I\%2orat\%20cortical\% 20astrocytes author P.\%20Pizzo author A.\%20Burgo author T.\% 20Pozzan author C.\%20Fasolato journal J\% 20Neurochem volume 79 issue 1 pages 98109 publication year 2001 doi 10.1046\%2Fj.1471-4159.2001.00539.x)

16 Grimaldi M, Maratos M, Verma A (2003) Transient receptor potential channel activation causes a novel form of [Ca 2+]I oscillations and is not involved in capacitative Ca 2+ entry in glial cells. J Neurosci. 23(11):4737 -4745. doi:23/11/4737

Google Scholar (https://scholar-googlecom.ezproxy.nihlibrary.nih.gov/scholar q Grimaldi\%20M\%2C\% 20Maratos\%20M\%2C\%2oVerma\%20A\%20\%282003\%29\%20Transient\% 2oreceptor\%2opotential\%2ochannel\%20activation\%20causes\%20a\% 2onovel\%2oform\%20of\%20\%5BCa\%202\%2B\%5DI\%20oscillations\%20and\% 2ois\%2onot\%2oinvolved\%20in\%20capacitative\%20Ca\%202\%2B\%20entry\% 20in\%20glial\%20cells.\%2OJ\%2oNeurosci.\%2023\%2811\%29\%3A4737\%E2\% 80\%934745.\%2odoi\%3A23\%2F11\%2F4737)

17 Golovina VA (2005) Visualization of localized store-operated calcium entry in mouse astrocytes. Close proximity to the endoplasmic reticulum. J Physiol 564(Pt 3):737-749. doi: 10.1113/jphysiol.2005.085035 (https://doiorg.ezproxy.nihlibrary.nih.gov/10.1113/jphysiol.2005.085035)

CrossRef (https://doiorg.ezproxy.nihlibrary.nih.gov/10.1113/jphysiol.2005.085035)

PubMed (http://www-ncbi-nlm-nihgov.ezproxy.nihlibrary.nih.gov/entrez/query.fcgi cmd Retrieve db PubMed dopt Abstract list uids 15731184)

PubMedCentral (http://www-ncbi-nlm-nihgov.ezproxy.nihlibrary.nih.gov/pmc/articles/PMC1464454)

Google Scholar

(http://scholar.google.com.ezproxy.nihlibrary.nih.gov/scholar lookup 
title Visualization\%20of\%2olocalized\%20store-operated\%20calcium\% 20entry\%20in\%2omouse\%20astrocytes.\%20Close\%2oproximity\%20to\% 2othe\%20endoplasmic\%20reticulum author VA.\%20Golovina journal J\% 20Physiol volume 564 issue $\mathrm{Pt} \% 203$ pages 737-

749 publication year 2005 doi 10.1113\%2Fjphysiol.2005.085035)

18 Shirakawa H, Sakimoto S, Nakao K, Sugishita A, Konno M, Iida S, Kusano A, Hashimoto E et al (2010) Transient receptor potential canonical 3 (TRPC3) mediates thrombin-induced astrocyte activation and upregulates its own expression in cortical astrocytes. J Neurosci 30(39):13116-13129.

doi: 10.1523/JNEUROSCI.1890-10.2010 (https://doi-

org.ezproxy.nihlibrary.nih.gov/10.1523/JNEUROSCI.1890-10.2010)

CrossRef (https://doi-

org.ezproxy.nihlibrary.nih.gov/10.1523/JNEUROSCI.1890-10.2010)

PubMed (http://www-ncbi-nlm-nih-

gov.ezproxy.nihlibrary.nih.gov/entrez/query.fcgi

cmd Retrieve db PubMed dopt Abstract list uids 20881130)

Google Scholar

(http://scholar.google.com.ezproxy.nihlibrary.nih.gov/scholar lookup

title Transient\%2oreceptor\%2opotential\%20canonical\%203\%20\%

28TRPC3\%29\%20mediates\%20thrombin-induced\%20astrocyte\% 20activation\%20and\%2oupregulates\%20its\%20own\%2oexpression\%20in\% 20cortical\%20astrocytes author H.\%20Shirakawa author S.\% 20Sakimoto author K.\%20Nakao author A.\%20Sugishita author M.\% 20Konno author S.\%20Iida author A.\%20Kusano author E.\% 20Hashimoto journal J\%20Neurosci volume 30 issue 39 pages 1311613129 publication year 2010 doi 10.1523\%2FJNEUROSCI.1890-10.2010)

19 Beskina O, Miller A, Mazzocco-Spezzia A, Pulina MV, Golovina VA (2007) Mechanisms of interleukin-1beta-induced Ca2+ signals in mouse cortical astrocytes: roles of store- and receptor-operated Ca2+ entry. Am J Physiol Cell Physiol 293(3):1103-1111. doi: 10.1152/ajpcell.00249.2007.-Many (https://doiorg.ezproxy.nihlibrary.nih.gov/10.1152/ajpcell.00249.2007.-Many)

CrossRef (https://doi-

org.ezproxy.nihlibrary.nih.gov/10.1152/ajpcell.00249.2007)

Google Scholar

(http://scholar.google.com.ezproxy.nihlibrary.nih.gov/scholar lookup title Mechanisms\%20of\%2ointerleukin-1beta-induced\%20Ca2\%2B\%

20signals\%20in\%2omouse\%2ocortical\%20astrocytes\%3A\%2oroles\%20of\% 20store-\%20and\%2oreceptor-operated\%20Ca2\%2B\%20entry author $0 . \%$ 20Beskina author A.\%20Miller author A.\%20MazzoccoSpezzia author MV.\%20Pulina author VA.\%20Golovina journal Am\% 20J\%20Physiol\%20Cell\%2oPhysiol volume 293 issue 3 pages 11031111 publication year 2007 doi 10.1152\%2Fajpcell.oo249.2007.-Many)

20 Hartmann J, Dragicevic E, Adelsberger H, Henning HA, Sumser M, Abramowitz J, Blum R, Dietrich A et al (2008) TRPC3 channels are required for synaptic transmission and motor coordination. Neuron 59(3):392-398. doi: 10.1016/j.neuron.2008.06.009 (https://doiorg.ezproxy.nihlibrary.nih.gov/10.1016/j.neuron.2008.06.009) CrossRef (https://doiorg.ezproxy.nihlibrary.nih.gov/10.1016/j.neuron.2008.06.009) 
PubMed (http://www-ncbi-nlm-nih-

gov.ezproxy.nihlibrary.nih.gov/entrez/query.fcgi

cmd Retrieve db PubMed dopt Abstract list uids 18701065)

PubMedCentral (http://www-ncbi-nlm-nih-

gov.ezproxy.nihlibrary.nih.gov/pmc/articles/PMC2643468)

Google Scholar

(http://scholar.google.com.ezproxy.nihlibrary.nih.gov/scholar lookup

title TRPC3\%20channels\%20are\%2orequired\%2ofor\%2osynaptic\%

20transmission\%20and\%20motor\%20coordination author J.\%

20Hartmann author E.\%2ODragicevic author H.\%

20Adelsberger author HA.\%20Henning author M.\%

20Sumser author J.\%20Abramowitz author R.\%20Blum author A.\%

2oDietrich journal Neuron volume 59 issue 3 pages 392-

398 publication year 2008 doi 10.1016\%2Fj.neuron.2008.06.009)

21 Dietrich A, Mederos YSM, Gollasch M, Gross V, Storch U, Dubrovska G, Obst $M$, Yildirim $E$ et al (2005) Increased vascular smooth muscle contractility in TRPC6-/- mice. Mol Cell Biol 25(16):6980-6989.

doi: 10.1128/MCB.25.16.6980-6989.2005 (https://doi-

org.ezproxy.nihlibrary.nih.gov/10.1128/MCB.25.16.6980-6989.2005)

CrossRef (https://doi-

org.ezproxy.nihlibrary.nih.gov/10.1128/MCB.25.16.6980-6989.2005)

PubMed (http://www-ncbi-nlm-nih-

gov.ezproxy.nihlibrary.nih.gov/entrez/query.fcgi

cmd Retrieve db PubMed dopt Abstract list uids 16055711)

PubMedCentral (http://www-ncbi-nlm-nih-

gov.ezproxy.nihlibrary.nih.gov/pmc/articles/PMC1190236)

Google Scholar

(http://scholar.google.com.ezproxy.nihlibrary.nih.gov/scholar lookup

title Increased\%20vascular\%20smooth\%2omuscle\%2ocontractility\%20in\%

20TRPC6\%E2\%88\%92\%2F\%E2\%88\%92\%20mice author A.\%

20Dietrich author YSM.\%20Mederos author M.\%

20Gollasch author V.\%20Gross author U.\%20Storch author G.\%

20Dubrovska author M.\%20Obst author E.\%20Yildirim journal Mol\%

20Cell\%20Biol volume 25 issue 16 pages 6980-

6989 publication year 2005 doi 10.1128\%2FMCB.25.16.6980-

6989.2005)

22 Perez-Leighton CE, Schmidt TM, Abramowitz J, Birnbaumer L, Kofuji P (2011) Intrinsic phototransduction persists in melanopsin-expressing ganglion cells lacking diacylglycerol-sensitive TRPC subunits. Eur J Neurosci 33(5):856-867. doi: 10.1111/j.1460-9568.2010.07583.x (https://doiorg.ezproxy.nihlibrary.nih.gov/10.1111/j.1460-9568.2010.07583.x)

CrossRef (https://doi-org.ezproxy.nihlibrary.nih.gov/10.1111/j.14609568.2010.07583.x)

PubMed (http://www-ncbi-nlm-nih-

gov.ezproxy.nihlibrary.nih.gov/entrez/query.fcgi

cmd Retrieve db PubMed dopt Abstract list uids 21261756)

PubMedCentral (http://www-ncbi-nlm-nih-

gov.ezproxy.nihlibrary.nih.gov/pmc/articles/PMC3076293)

Google Scholar

(http://scholar.google.com.ezproxy.nihlibrary.nih.gov/scholar lookup 
title Intrinsic\%2ophototransduction\%2opersists\%2oin\%2omelanopsinexpressing\%2oganglion\%2ocells\%2olacking\%2odiacylglycerol-sensitive\% 20TRPC\%20subunits author CE.\%20Perez-Leighton author TM.\% 20Schmidt author J.\%20Abramowitz author L.\% 20Birnbaumer author P.\%20Kofuji journal Eur\%20J\% 20Neurosci volume 33 issue 5 pages 856867 publication year 2011 doi 10.1111\%2Fj.1460-9568.2010.07583.x)

23 Longa E , Weinstein PR, Carlson S, Cummins R (1989) Reversible middle cerebral artery occlusion without craniectomy in rats. Stroke 20(1):84-91 Google Scholar (https://scholar-googlecom.ezproxy.nihlibrary.nih.gov/scholar q Longa\%20E \%2C\% 2oWeinstein\%20PR\%2C\%20Carlson\%20S\%2C\%20Cummins\%20R\%20\% 281989\%29\%2oReversible\%2omiddle\%20cerebral\%2oartery\%2oocclusion\% 20without\%20craniectomy\%20in\%2orats.\%20Stroke\%2020\%281\%29\% 3А84\%E2\%80\%9391)

24 Suzuki K, Ikegaya Y, Matsuura S, Kanai Y, Endou H, Matsuki N (2001) Transient upregulation of the glial glutamate transporter GLAST in response to fibroblast growth factor, insulin-like growth factor and epidermal growth factor in cultured astrocytes. J Cell Sci 114(Pt20):3717-3725

PubMed (http://www-ncbi-nlm-nihgov.ezproxy.nihlibrary.nih.gov/entrez/query.fcgi cmd Retrieve db PubMed dopt Abstract list uids 11707523) Google Scholar (http://scholar.google.com.ezproxy.nihlibrary.nih.gov/scholar lookup title Transient\%20upregulation\%20of\%2othe\%2oglial\%2oglutamate\% 2otransporter\%20GLAST\%2oin\%2oresponse\%20to\%2ofibroblast\% 20growth\%2ofactor\%2C\%2oinsulin-like\%2ogrowth\%2ofactor\%20and\% 2oepidermal\%2ogrowth\%2ofactor\%20in\%20cultured\%

20astrocytes author K.\%20Suzuki author Y.\%20Ikegaya author S.\% 20Matsuura author Y.\%20Kanai author H.\%20Endou author N.\% 20Matsuki journal J\%20Cell\% 20Sci volume 114 issue Pt20 pages 3717-3725 publication year 2001)

25 Vermes I, Haanen C, Steffens-Nakken H, Reutelingsperger C (1995) A novel assay for apoptosis. Flow cytometric detection of phosphatidylserine expression on early apoptotic cells using fluorescein labelled Annexin V. J Immunol Methods 184(1):39-51 doi:002217599500072I CrossRef (https://doi-org.ezproxy.nihlibrary.nih.gov/10.1016/0022-1759 (95)00072-I)

PubMed (http://www-ncbi-nlm-nihgov.ezproxy.nihlibrary.nih.gov/entrez/query.fcgi cmd Retrieve db PubMed dopt Abstract list uids 7622868)

Google Scholar

(http://scholar.google.com.ezproxy.nihlibrary.nih.gov/scholar lookup title A\%2onovel\%20assay\%2ofor\%20apoptosis.\%2oFlow\%20cytometric\% 2odetection\%20of\%2ophosphatidylserine\%20expression\%20on\%20early\% 20apoptotic\%20cells\%2ousing\%2ofluorescein\%2olabelled\%20Annexin\% $20 \mathrm{~V}$ author I.\%20Vermes author C.\%20Haanen author H.\%20SteffensNakken author C.\%20Reutelingsperger journal J\%20Immunol\% 20Methods volume 184 issue 1 pages 39-51 publication year 1995) 
Li X, Blizzard KK, eng , DeVries AC, Hurn PD, McCullough LD (2004) Chronic behavioral testing after focal ischemia in the mouse: functional recovery and the effects of gender. Exp Neurol 187(1):94-104.

doi: 10.1016/j.expneurol.2004.01.004 (https://doi-

org.ezproxy.nihlibrary.nih.gov/10.1016/j.expneurol.2004.01.004)

CrossRef (https://doi-

org.ezproxy.nihlibrary.nih.gov/10.1016/j.expneurol.2004.01.004)

PubMed (http://www-ncbi-nlm-nihgov.ezproxy.nihlibrary.nih.gov/entrez/query.fcgi

cmd Retrieve db PubMed dopt Abstract list uids 15081592)

Google Scholar

(http://scholar.google.com.ezproxy.nihlibrary.nih.gov/scholar lookup title Chronic\%2obehavioral\%2otesting\%20after\%2ofocal\%2oischemia\% 20in\%20the\%20mouse\%3A\%2ofunctional\%2orecovery\%20and\%20the\% 20effects\%20of\%20gender author X.\%20Li author KK.\%

20Blizzard author \%20 eng author AC.\%20DeVries author PD.\% 20Hurn author LD.\%20McCullough journal Exp\%

20Neurol volume 187 issue 1 pages 94-

104 publication year 2004 doi 10.1016\%2Fj.expneurol.2004.01.004)

27 Wang C, Pei A, Chen J, Yu H, Sun ML, Liu CF, Xu X (2012) A natural coumarin derivative esculetin offers neuroprotection on cerebral ischemia/reperfusion injury in mice. J Neurochem 121(6):1007-1013. doi: 10.1111/j.1471-4159.2012.07744.x (https://doiorg.ezproxy.nihlibrary.nih.gov/10.1111/j.1471-4159.2012.07744.x) CrossRef (https://doi-org.ezproxy.nihlibrary.nih.gov/10.1111/j.14714159.2012.07744.x) PubMed (http://www-ncbi-nlm-nihgov.ezproxy.nihlibrary.nih.gov/entrez/query.fcgi cmd Retrieve db PubMed dopt Abstract list uids 22458555) Google Scholar (http://scholar.google.com.ezproxy.nihlibrary.nih.gov/scholar lookup title A\%2onatural\%2ocoumarin\%2oderivative\%20esculetin\%20offers\% 2oneuroprotection\%20on\%2ocerebral\%2oischemia\%2Freperfusion\% 20injury\%20in\%20mice author C.\%20Wang author A.\% 20Pei author J.\%20Chen author H.\%2OYu author ML.\% 20Sun author CF.\%20Liu author X.\%20Xu journal J\% 20Neurochem volume 121 issue 6 pages 10071013 publication year 2012 doi 10.1111\%2Fj.1471-4159.2012.07744.x)

28 Venkatachalam K, heng F, Gill DL (2003) Regulation of canonical transient receptor potential (TRPC) channel function by diacylglycerol and protein kinase C. J Biol Chem 278(31):29031-29040. doi: 10.1074/jbc.M302751200 (https://doi-org.ezproxy.nihlibrary.nih.gov/10.1074/jbc.M302751200) CrossRef (https://doiorg.ezproxy.nihlibrary.nih.gov/10.1074/jbc.M302751200)

PubMed (http://www-ncbi-nlm-nihgov.ezproxy.nihlibrary.nih.gov/entrez/query.fcgi cmd Retrieve db PubMed dopt Abstract list uids 12721302) Google Scholar (http://scholar.google.com.ezproxy.nihlibrary.nih.gov/scholar lookup title Regulation\%20of\%20canonical\%20transient\%20receptor\% 
2opotential\%20\%28TRPC\%29\%20channel\%2ofunction\%2oby\% 20diacylglycerol\%20and\%2oprotein\%2okinase\%20C author K.\% 20Venkatachalam author F.\%20 heng author DL.\%20Gill journal J\% 20Biol\%20Chem volume 278 issue 31 pages 2903129040 publication year 2003 doi 10.1074\%2Fjbc.M302751200)

29 Liao Y, Erxleben C, Yildirim E, Abramowitz J, Armstrong DL, Birnbaumer L (2007) Orai proteins interact with TRPC channels and confer responsiveness to store depletion. Proc Natl Acad Sci U S A 104(11):4682-4687.

doi: 10.1073/pnas.0611692104 (https://doi-

org.ezproxy.nihlibrary.nih.gov/10.1073/pnas.0611692104)

CrossRef (https://doi-

org.ezproxy.nihlibrary.nih.gov/10.1073/pnas.0611692104)

PubMed (http://www-ncbi-nlm-nih-

gov.ezproxy.nihlibrary.nih.gov/entrez/query.fcgi

cmd Retrieve db PubMed dopt Abstract list uids 17360584)

PubMedCentral (http://www-ncbi-nlm-nih-

gov.ezproxy.nihlibrary.nih.gov/pmc/articles/PMC1838661)

Google Scholar

(http://scholar.google.com.ezproxy.nihlibrary.nih.gov/scholar lookup

title Orai\%2oproteins\%2ointeract\%20with\%20TRPC\%20channels\%20and\%

20confer\%2oresponsiveness\%20to\%20store\%20depletion author Y.\%

20 Liao author C.\%20Erxleben author E.\%20Yildirim author J.\%

20Abramowitz author DL.\%20Armstrong author L.\%

2oBirnbaumer journal Proc\%20Natl\%20Acad\%20Sci\%20U\%20S\%

$20 \mathrm{~A}$ volume 104 issue 11 pages 4682 -

4687 publication year 2007 doi 10.1073\%2Fpnas.0611692104)

30 Liao Y, Erxleben C, Abramowitz J, Flockerzi V, hu MX, Armstrong DL, Birnbaumer L (2008) Functional interactions among Orai1, TRPCs, and STIM1 suggest a STIM-regulated heteromeric Orai/TRPC model for SOCE/Icrac channels. Proc Natl Acad Sci U S A 105(8):2895-2900.

doi: $10.1073 /$ pnas.0712288105 (https://doi-

org.ezproxy.nihlibrary.nih.gov/10.1073/pnas.0712288105)

CrossRef (https://doi-

org.ezproxy.nihlibrary.nih.gov/10.1073/pnas.0712288105)

PubMed (http://www-ncbi-nlm-nih-

gov.ezproxy.nihlibrary.nih.gov/entrez/query.fcgi

cmd Retrieve db PubMed dopt Abstract list uids 18287061)

PubMedCentral (http://www-ncbi-nlm-nih-

gov.ezproxy.nihlibrary.nih.gov/pmc/articles/PMC2268556)

Google Scholar

(http://scholar.google.com.ezproxy.nihlibrary.nih.gov/scholar lookup title Functional\%2ointeractions\%20among\%20Orai1\%2C\%20TRPCs\%2C\% 20and\%20STIM1\%20suggest\%20a\%20STIM-regulated\%2oheteromeric\% 20Orai\%2FTRPC\%2omodel\%2ofor\%20SOCE\%2FIcrac\%

20channels author Y.\%20Liao author C.\%20Erxleben author J.\%

20Abramowitz author V.\%20Flockerzi author MX.\%

$20 \mathrm{hu}$ author DL.\%20Armstrong author L.\%

20Birnbaumer journal Proc\%20Natl\%20Acad\%20Sci\%20U\%20S\%

$20 \mathrm{~A}$ volume 105 issue 8 pages 2895-

2900 publication year 2008 doi 10.1073\%2Fpnas.0712288105) 
31 Liao Y, Plummer NW, George MD, Abramowitz J, hu MX, Birnbaumer L (2009) A role for Orai in TRPC-mediated Ca2+ entry suggests that a TRPC:Orai complex may mediate store and receptor operated Ca2+ entry. Proc Natl Acad Sci U S A 106(9):3202-3206. doi: 10.1073/pnas.0813346106 (https://doi-org.ezproxy.nihlibrary.nih.gov/10.1073/pnas.0813346106) CrossRef (https://doiorg.ezproxy.nihlibrary.nih.gov/10.1073/pnas.0813346106)

PubMed (http://www-ncbi-nlm-nihgov.ezproxy.nihlibrary.nih.gov/entrez/query.fcgi

cmd Retrieve db PubMed dopt Abstract list uids 19221033)

PubMedCentral (http://www-ncbi-nlm-nihgov.ezproxy.nihlibrary.nih.gov/pmc/articles/PMC2651283)

Google Scholar

(http://scholar.google.com.ezproxy.nihlibrary.nih.gov/scholar lookup title A\%2orole\%2ofor\%20Orai\%20in\%2oTRPC-mediated\%20Ca2\%2B\% 2oentry\%20suggests\%20that\%20a\%20TRPC\%3AOrai\%20complex\%20may\% 2omediate\%20store\%20and\%2oreceptor\%20operated\%20Ca2\%2B\% 20entry author Y.\%20Liao author NW.\%20Plummer author MD.\% 20George author J.\%20Abramowitz author MX.\%20 hu author L.\% 20Birnbaumer journal Proc\%20Natl\%20Acad\%20Sci\%20U\%20S\% $20 \mathrm{~A}$ volume 106 issue 9 pages 3202 3206 publication year 2009 doi 10.1073\%2Fpnas.0813346106)

32 Montell C, Birnbaumer L, Flockerzi V (2002) The TRP channels, a remarkably functional family. Cell 108(5):595-598. doi: 10.1016/Soo92-8674 (02)00670-o (https://doi-org.ezproxy.nihlibrary.nih.gov/10.1016/So0928674(02)00670-0) CrossRef (https://doi-org.ezproxy.nihlibrary.nih.gov/10.1016/Soo92-8674 (02)00670-0)

PubMed (http://www-ncbi-nlm-nihgov.ezproxy.nihlibrary.nih.gov/entrez/query.fcgi

cmd Retrieve db PubMed dopt Abstract list uids 11893331)

Google Scholar

(http://scholar.google.com.ezproxy.nihlibrary.nih.gov/scholar lookup title The\%20TRP\%2ochannels\%2C\%20a\%2oremarkably\%2ofunctional\% 2ofamily author C.\%20Montell author L.\%20Birnbaumer author V.\% 20Flockerzi journal Cell volume 108 issue 5 pages 595598 publication year 2002 doi 10.1016\%2FSo092-8674\%2802\% 2900670-0)

33 Goel M, Sinkins WG, Schilling WP (2002) Selective association of TRPC channel subunits in rat brain synaptosomes. J Biol Chem 277(50):48303 -48310. doi: 10.1074/jbc.M207882200 (https://doiorg.ezproxy.nihlibrary.nih.gov/10.1074/jbc.M207882200)

CrossRef (https://doi-

org.ezproxy.nihlibrary.nih.gov/10.1074/jbc.M207882200)

PubMed (http://www-ncbi-nlm-nih-

gov.ezproxy.nihlibrary.nih.gov/entrez/query.fcgi

cmd Retrieve db PubMed dopt Abstract list uids 12377790)

Google Scholar

(http://scholar.google.com.ezproxy.nihlibrary.nih.gov/scholar lookup title Selective\%20association\%20of\%20TRPC\%20channel\%2osubunits\% 
20in\%2orat\%2obrain\%2osynaptosomes author M.\% 20Goel author WG.\%20Sinkins author WP.\%20Schilling journal J\% 20Biol\%20Chem volume 277 issue 50 pages 4830348310 publication year 2002 doi 10.1074\%2Fjbc.M207882200)

34 Birnbaumer L, hu X, Jiang M, Boulay G, Peyton M, Vannier B, Brown D, Platano D, Sadeghi H, Stefani E, Birnbaumer M (1996) On the molecular basis and regulation of cellular capacitative calcium entry: roles for Trp proteins. Proc Natl Acad Sci U S A 93(26):15195-15202

Google Scholar (https://scholar-google-

com.ezproxy.nihlibrary.nih.gov/scholar q Birnbaumer\%20L\%2C\%20 hu\% 20X\%2C\%20Jiang\%20M\%2C\%2oBoulay\%20G\%2C\%2oPeyton\%20M\%2C\% 20Vannier\%20B\%2C\%2oBrown\%20D\%2C\%20Platano\%20D\%2C\% 2OSadeghi\%2oH\%2C\%2OStefani\%2oE\%2C\%2oBirnbaumer\%2oM\%20\% 281996\%29\%20On\%20the\%2omolecular\%2obasis\%20and\%2oregulation\% 20of\%20cellular\%2ocapacitative\%2ocalcium\%2oentry\%3A\%2oroles\% 2ofor\%20Trp\%2oproteins.\%2oProc\%20Natl\%20Acad\%20Sci\%20U\%20S\% 20A\%2093\%2826\%29\%3A15195\%E2\%80\%9315202)

35 Sergeeva M, Strokin M, Wang H, Ubl JJ, Reiser G (2003) Arachidonic acid in astrocytes blocks $\mathrm{Ca} 2+$ oscillations by inhibiting store-operated $\mathrm{Ca} 2+$ entry, and causes delayed Ca2+ influx. Cell Calcium 33(4):283-292.

doi: 10.1016/so143-416o(o3)ooo11-3 (https://doi-

org.ezproxy.nihlibrary.nih.gov/10.1016/s0143-416o(03)ooo11-3)

CrossRef (https://doi-org.ezproxy.nihlibrary.nih.gov/10.1016/So143-4160

(03)ooo11-3)

PubMed (http://www-ncbi-nlm-nih-

gov.ezproxy.nihlibrary.nih.gov/entrez/query.fcgi

cmd Retrieve db PubMed dopt Abstract list uids 12618149)

Google Scholar

(http://scholar.google.com.ezproxy.nihlibrary.nih.gov/scholar lookup

title Arachidonic\%20acid\%20in\%2Oastrocytes\%2oblocks\%20Ca2\%2B\%

20oscillations\%20by\%20inhibiting\%20store-operated\%20Ca2\%2B\%

20entry\%2C\%2Oand\%20causes\%20delayed\%20Ca2\%2B\%

2oinflux author M.\%20Sergeeva author M.\%20Strokin author H.\% 20Wang author JJ.\%20Ubl author G.\%20Reiser journal Cell\%

20Calcium volume 33 issue 4 pages 283-

292 publication year 2003 doi $10.1016 \% 2$ Fso143-4160\%2803\%

2900011-3)

36 Agulhon C, Petravicz J, McMullen AB, Sweger EJ, Minton SK, Taves SR, Casper KB, Fiacco TA et al (2008) What is the role of astrocyte calcium in neurophysiology Neuron 59(6):932-946.

doi: 10.1016/j.neuron.2008.09.004 (https://doi-

org.ezproxy.nihlibrary.nih.gov/10.1016/j.neuron.2008.09.004)

CrossRef (https://doi-

org.ezproxy.nihlibrary.nih.gov/10.1016/j.neuron.2008.09.004)

PubMed (http://www-ncbi-nlm-nih-

gov.ezproxy.nihlibrary.nih.gov/entrez/query.fcgi

cmd Retrieve db PubMed dopt Abstract list uids 18817732)

PubMedCentral (http://www-ncbi-nlm-nih-

gov.ezproxy.nihlibrary.nih.gov/pmc/articles/PMC3623689) 


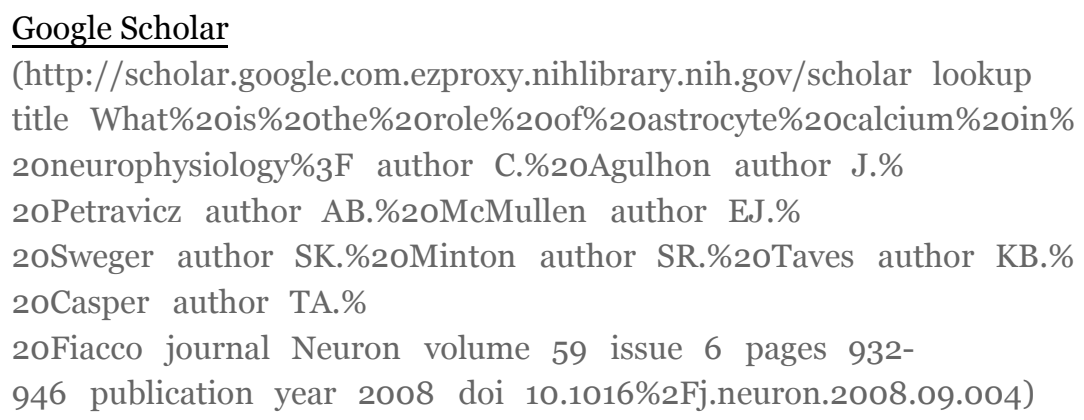

37 Barajas M, Andrade A, Hernandez-Hernandez O, Felix R, Arias-Montano JA (2008) Histamine-induced Ca2+ entry in human astrocytoma U373 MG cells: evidence for involvement of store-operated channels. J Neurosci Res 86 (15):3456-3468. doi: 10.1002/jnr.21784 (https://doiorg.ezproxy.nihlibrary.nih.gov/10.1002/jnr.21784)

CrossRef (https://doi-org.ezproxy.nihlibrary.nih.gov/10.1002/jnr.21784)

PubMed (http://www-ncbi-nlm-nihgov.ezproxy.nihlibrary.nih.gov/entrez/query.fcgi cmd Retrieve db PubMed dopt Abstract list uids 18627030) Google Scholar (http://scholar.google.com.ezproxy.nihlibrary.nih.gov/scholar lookup title Histamine-induced\%20Ca2\%2B\%20entry\%20in\%2ohuman\% 20astrocytoma\%20U373\%20MG\%20cells\%3A\%20evidence\%2ofor\% 2oinvolvement\%20of\%20store-operated\%20channels author M.\% 20Barajas author A.\%20Andrade author O.\%20HernandezHernandez author R.\%20Felix author JA.\%20AriasMontano journal J\%20Neurosci\% 20Res volume 86 issue 15 pages 3456 3468 publication year 2008 doi $10.1002 \% 2 F j n r .21784$ )

38 Nakao K, Shirakawa H, Sugishita A, Matsutani I, Niidome T, Nakagawa T, Kaneko S (2008) Ca2+ mobilization mediated by transient receptor potential canonical 3 is associated with thrombin-induced morphological changes in 1321N1 human astrocytoma cells. J Neurosci Res 86(12):2722-2732.

doi: 10.1002/jnr.21711 (https://doiorg.ezproxy.nihlibrary.nih.gov/10.1002/jnr.21711)

CrossRef (https://doi-org.ezproxy.nihlibrary.nih.gov/10.1002/jnr.21711)

PubMed (http://www-ncbi-nlm-nihgov.ezproxy.nihlibrary.nih.gov/entrez/query.fcgi cmd Retrieve db PubMed dopt Abstract list uids 18478545)

Google Scholar

(http://scholar.google.com.ezproxy.nihlibrary.nih.gov/scholar lookup

title Ca2\%2B\%2omobilization\%2omediated\%2oby\%2otransient\% 2oreceptor\%2opotential\%2ocanonical\%203\%20is\%20associated\%20with\% 20thrombin-induced\%20morphological\%20changes\%20in\%201321N1\% 20human\%20astrocytoma\%20cells author K.\%20Nakao author H.\% 20Shirakawa author A.\%20Sugishita author I.\% 20Matsutani author T.\%20Niidome author T.\%20Nakagawa author S.\% 2oKaneko journal J\%20Neurosci\% 20Res volume 86 issue 12 pages 27222732 publication year 2008 doi 10.1002\%2Fjnr.21711) 
Wang L, hang Y, Asakawa T, Li W, Han S, Li Q, Xiao B, Namba H et al (2015) Neuroprotective effect of neuroserpin in oxygen-glucose deprivationand reoxygenation-treated rat astrocytes in vitro. PLoS One 10(4):e0123932. doi: 10.1371/journal.pone.0123932 (https://doi-

org.ezproxy.nihlibrary.nih.gov/10.1371/journal.pone.0123932)

CrossRef (https://doi-

org.ezproxy.nihlibrary.nih.gov/10.1371/journal.pone.0123932)

PubMed (http://www-ncbi-nlm-nihgov.ezproxy.nihlibrary.nih.gov/entrez/query.fcgi

cmd Retrieve db PubMed dopt Abstract list uids 25874935)

PubMedCentral (http://www-ncbi-nlm-nih-

gov.ezproxy.nihlibrary.nih.gov/pmc/articles/PMC4395230)

Google Scholar

(http://scholar.google.com.ezproxy.nihlibrary.nih.gov/scholar lookup

title Neuroprotective\%20effect\%20of\%2oneuroserpin\%20in\%20oxygen-

glucose\%2odeprivation-\%20and\%2oreoxygenation-treated\%2orat\%

20astrocytes\%20in\%20vitro author L.\%20Wang author Y.\%

20 hang author T.\%20Asakawa author W.\%20Li author S.\%

20Han author Q.\%2OLi author B.\%20Xiao author H.\%

20Namba journal PLoS\%

20One volume 10 issue 4 pages e0123932 publication year 2015 doi

10.1371\%2Fjournal.pone.0123932)

40 White BC, Sullivan JM, DeGracia DJ, O Neil BJ, Neumar RW, Grossman LI, Rafols JA, Krause GS (2000) Brain ischemia and reperfusion: molecular mechanisms of neuronal injury. J Neurol Sci 179(S1-2):1-33.

doi: 10.1016/So022-510X(oo)o0386-5 (https://doiorg.ezproxy.nihlibrary.nih.gov/10.1016/Soo22-510X(00)00386-5)

41 Noshita N, Lew n A, Sugawara T, Chan PH (2001) Evidence of phosphorylation of Akt and neuronal survival after transient focal cerebral ischemia in mice. J Cereb Blood Flow Metab 21(12):1442-1450.

doi: 10.1097/00004647-200112000-00009 (https://doi-

org.ezproxy.nihlibrary.nih.gov/10.1097/00004647-200112000-00009)

CrossRef (https://doi-org.ezproxy.nihlibrary.nih.gov/10.1097/00004647200112000-00009)

PubMed (http://www-ncbi-nlm-nih-

gov.ezproxy.nihlibrary.nih.gov/entrez/query.fcgi

cmd Retrieve db PubMed dopt Abstract list uids 11740206)

Google Scholar

(http://scholar.google.com.ezproxy.nihlibrary.nih.gov/scholar lookup

title Evidence\%20of\%2ophosphorylation\%20of\%20Akt\%20and\%

2oneuronal\%2osurvival\%20after\%2otransient\%2ofocal\%2ocerebral\% 20ischemia\%20in\%2omice author N.\%20Noshita author A.\%20Lew\% C3\%A9n author T.\%20Sugawara author PH.\%20Chan journal J\% 20Cereb\%2oBlood\%2oFlow\%20Metab volume 21 issue 12 pages 14421450 publication year 2001 doi 10.1097\%2Foooo4647-20011200000009)

42 Li SY, Yang D, Fu J, Woo T, Wong D, Lo AC (2012) Lutein enhances survival and reduces neuronal damage in a mouse model of ischemic stroke. Neurobiol Dis 45(1):624-632. doi: 10.1016/j.nbd.2011.10.008 (https://doiorg.ezproxy.nihlibrary.nih.gov/10.1016/j.nbd.2011.10.008) 
CrossRef (https://doi-

org.ezproxy.nihlibrary.nih.gov/10.1016/j.nbd.2011.10.008)

PubMed (http://www-ncbi-nlm-nih-

gov.ezproxy.nihlibrary.nih.gov/entrez/query.fcgi

cmd Retrieve db PubMed dopt Abstract list uids 22024715)

Google Scholar

(http://scholar.google.com.ezproxy.nihlibrary.nih.gov/scholar lookup

title Lutein\%20enhances\%20survival\%20and\%2oreduces\%2oneuronal\%

20damage\%20in\%20a\%20mouse\%2omodel\%20of\%20ischemic\%

20stroke author SY.\%20Li author D.\%20Yang author J.\%

20Fu author T.\%20Woo author D.\%20Wong author AC.\%

20Lo journal Neurobiol\%20Dis volume 45 issue 1 pages 624-

632 publication year 2012 doi 10.1016\%2Fj.nbd.2011.10.008)

43 Paria BC, Malik AB, Kwiatek AM, Rahman A, May MJ, Ghosh S, Tiruppathi C (2003) Tumor necrosis factor-alpha induces nuclear factor-kappaB-

dependent TRPC1 expression in endothelial cells. J Biol Chem 278(39):37195

-37203. doi: 10.1074/jbc.M304287200 (https://doi-

org.ezproxy.nihlibrary.nih.gov/10.1074/jbc.M304287200)

CrossRef (https://doi-

org.ezproxy.nihlibrary.nih.gov/10.1074/jbc.M304287200)

PubMed (http://www-ncbi-nlm-nih-

gov.ezproxy.nihlibrary.nih.gov/entrez/query.fcgi

cmd Retrieve db PubMed dopt Abstract list uids 12855710)

Google Scholar

(http://scholar.google.com.ezproxy.nihlibrary.nih.gov/scholar lookup

title Tumor\%2onecrosis\%2ofactor-alpha\%2oinduces\%2onuclear\%2ofactor-

kappaB-dependent\%20TRPC1\%20expression\%20in\%20endothelial\%

20cells author BC.\%20Paria author AB.\%20Malik author AM.\%

20Kwiatek author A.\%20Rahman author MJ.\%20May author S.\%

20Ghosh author C.\%20Tiruppathi journal J\%20Biol\%

20Chem volume 278 issue 39 pages 37195-

37203 publication year 2003 doi 10.1074\%2Fjbc.M304287200)

44 Paria BC, Bair AM, Xue J, Yu Y, Malik AB, Tiruppathi C (2006) Ca2+ influx induced by protease-activated receptor-1 activates a feed-forward mechanism of TRPC1 expression via nuclear factor-kappaB activation in endothelial cells. J Biol Chem 281(30):20715-20727. doi: 10.1074/jbc.M600722200

(https://doi-org.ezproxy.nihlibrary.nih.gov/10.1074/jbc.M600722200)

CrossRef (https://doi-

org.ezproxy.nihlibrary.nih.gov/10.1074/jbc.M600722200)

PubMed (http://www-ncbi-nlm-nih-

gov.ezproxy.nihlibrary.nih.gov/entrez/query.fcgi

cmd Retrieve db PubMed dopt Abstract list uids 16709572)

Google Scholar

(http://scholar.google.com.ezproxy.nihlibrary.nih.gov/scholar lookup

title Ca2\%2B\%20influx\%2oinduced\%20by\%2oprotease-activated\%

2oreceptor-1\%20activates\%20a\%2ofeed-forward\%2omechanism\%20of\%

20TRPC1\%20expression\%20via\%2onuclear\%2ofactor-kappaB\%

20activation\%20in\%20endothelial\%20cells author BC.\%

20Paria author AM.\%20Bair author J.\%20Xue author Y.\%

20Yu author AB.\%20Malik author C.\%20Tiruppathi journal J\%20Biol\%

https://link-springer-com.ezproxy.nihlibrary.nih.gov/article/10.1007\%2Fs12035-016-0227-2 
TRPC3/6/7 Knockdown Protects the Brain from Cerebral Ischemia Injury via Astrocyte Apoptosis Inhi... Page 35 of 36

20Chem volume 281 issue 30 pages 20715-

20727 publication year 2006 doi 10.1074\%2Fjbc.M600722200)

\section{Copyright information}

\section{Springer Science+Business Media New}

\section{York 2016}

About this article

ite this arti le as:

Chen, , u, M, e, et al Mol Neurobiol 2017547555 https doi org e pro y nihlibrary nih gov 101007 s12035

01602272

e ei ed

04 une 2016

e ted

10 ctober 2016

\section{First Online}

08 November 2016

\section{Ol}

https doi org e pro y nihlibrary nih gov 101007 s12035 01602272

\section{ublisher $\mathrm{Na}$ e}

pringer

\section{rint I $\mathrm{N}$}

08937648

\section{Online I N}

15591182

About this ournal

eprints and ermissions 